\title{
Cyclic Nanoindentation and Nano-Impact Fatigue Mechanisms of Functionally Graded TiN/TiNi Film
}

\author{
N. H. Faisal ${ }^{1} \cdot$ Anil K. Prathuru $^{1} \cdot$ Saurav Goel $^{2} \cdot$ R. Ahmed $^{3} \cdot$ M. G. Droubi ${ }^{1}$ \\ B. D. Beake $\mathbf{4}^{4}$ Y. Q. Fu
}

Published online: 9 March 2017

(c) The Author(s) 2017. This article is published with open access at Springerlink.com

\begin{abstract}
The mechanisms of nanoscale fatigue of functionally graded TiN/TiNi films have been studied using multiple-loading cycle nanoindentation and nano-impact tests. The functionally graded films were sputter deposited onto silicon substrates, in which the TiNi film provides pseudo-elasticity and shape memory behaviour, while a top TiN surface layer provides tribological and anti-corrosion properties. Nanomechanical tests were performed to investigate the localised film performance and failure modes of the functionally graded film using both Berkovich and conical indenters with loads between $100 \mu \mathrm{N}$ and $500 \mathrm{mN}$. The loading history was critical to define film failure modes (i.e. backward depth deviation) and the pseudo-elastic/shape memory effect of the functionally graded layer. The results were sensitive to the applied load, loading mode (e.g. semi-static, dynamic) and probe geometry. Based on indentation force-depth profiles, depth-time data and post-test surface observations of films, it was concluded that the shape of the indenter is critical to induce localised indentation stress and film failure, and
\end{abstract}

\footnotetext{
N. H. Faisal

N.H.Faisal@rgu.ac.uk

Richard.Fu@northumbria.ac.uk

1 School of Engineering, Robert Gordon University, Garthdee Road, Aberdeen AB10 7GJ, UK

2 School of Transport, Aerospace and Manufacturing, Cranfield University, Cranfield MK43 0AL, UK

3 School of Engineering and Physical Sciences, Heriot-Watt University, Edinburgh EH14 4AS, UK

4 Micro Materials Ltd, Wrexham LL13 7YL, UK

5 Faculty of Engineering and Environment, University of Northumbria, Newcastle upon Tyne NE1 8ST, UK
}

$\triangle$ Y. Q. Fu generation of pseudo-elasticity at a lower load range. Finite-element simulation of the elastic loading process indicated that the location of subsurface maximum stress near the interface influences the backward depth deviation type of film failure.

Keywords Nitinol - Shape memory alloys - Biomedical · Multiple-loading cycle nanoindentation $\cdot$ Nano-impact (fatigue)

\section{Introduction}

Titanium-nickel (TiNi) alloys and thin films are commonly used shape memory alloys (SMAs) for biomedical applications, with two distinctive features of pseudo-elasticity (or superelasticity) and shape memory effect. Studies of localised cyclic contact stresses (using multiple-loading cycle nanoindentation and nano-impact) and their influences to the SMAs and thin films can provide valuable information for their component designs and applications. This can be realised through nanoindentation by controlling loading conditions and geometry of contact probes to investigate deformation behaviours of multilayer structures at highly concentrated stressed conditions. This paper is aiming to investigate, for the first time, how by varying levels of localised contact, the cyclic stresses induced on the top layer TiN film on a TiNi-based SMA thin film affect the nanoscale fatigue failure modes and superelastic/ shape recovery behaviour.

TiNi-based SMA thin films, with their shape memory effect, pseudo-elasticity, biocompatibility, deformation compatibility and high damping capacity, have found applications in biomedical and microelectromechanical systems (MEMS) [1], Fu and Du [2], Fu et al. [3-11]. 
Different micro-devices, such as micro-grippers, micromirrors and micro-cages have been designed and demonstrated using TiNi-based SMA thin films (Fu et al. [12-15]. Concerns, however, remain for the applications of thin-film SMA materials, because of their unsatisfactory mechanical and tribological properties, chemical resistance and biological reliability, such as, potential nickel release $[16,17]$ and poor localised corrosion in chloride containing environments $[18,19]$. Therefore, there have been some previous studies on the surface and biocompatibility of TiNi bulk materials [20, 21]. It is generally agreed that the presence of an adherent and stable $\mathrm{TiO}_{2}$ film on TiNi bulk alloy surface is beneficial to its corrosion resistance and biocompatibility, but this layer is generally thin (up to tens of nanometres) [16, 22]. The mechanical properties of $\mathrm{TiO}_{2}$ and TiNi are vastly different, and this thin oxide layer can easily be damaged during deformation or complex interaction involving wear [23, 24]. For medical applications using the TiNi alloys, it is crucial to optimise the processing of their passivation layer, and prevent surface layer degradation. Ion implantation [25], gas nitriding [26-28] and TiN coating $[18,29]$ have been employed to improve surface properties of the bulk TiNi alloys. Similarly, after applying a TiN layer on the TiNi films, the shape memory and pseudo-elastic behaviour of the bulk film are retained, while the modified surface layer renders new surface properties (biocompatibility, wear and corrosion resistance). Our previous work $[1,30]$ explored the deposition of a functionally graded TiN/TiNi layer to fulfil this purpose. The presence of an adherent and hard TiN layer $(200 \mathrm{~nm})$ on TiNi film $(3.5 \mu \mathrm{m})$ formed a good passivation layer which improved the overall hardness, load bearing capacity and tribological properties without sacrificing the phase transformation and the shape memory effects of the underlying TiNi thin-film layer (Fu and $\mathrm{Du}$ [30].

During applications, the TiNi films may suffer from various failure damages during cyclic loading conditions (tensile, compressive, shear or combination of these stresses). Shape memory micro-devices will be widely used in micro- or nanoscale loading or actuation functions, which could cause microscale indentation, scratch, fatigue and impact, etc., ranging from elastic/plastic deformations to catastrophic failures. These films should have low residual stresses to prevent deformation of devices, and have abilities to resist crack initiation/propagation, and surface scratch and wear.

The current work is aiming to investigate the nanoindentation and nano-impact responses of functionally graded TiN/TiNi thin films under multiple-loading cycles. In contrast to a few reports about the nanoindentation of shape memory thin films primarily focusing on the shape memory effects, pseudo-elastic behaviour, or mechanical properties, etc. [31-36], this work sheds new light on the multiple- loading nanoindentation (low-cycle fatigue) and nano-impact (relatively high-cycle fatigue) performance of functionally graded TiN/TiNi films. The multiple-loading nanoindentation tests are useful to measure hardness and elastic modulus versus depth in the cases of thin-film and thick coatings, whereas, the multicycle tests are performed at a constant load to investigate the dynamic indentation response to study localised fatigue behaviour. Since the indentation fatigue damage starts with deformation, crack initiation and propagation, the interpretation of the multiple-loading nanoindentation and nano-impact-based fatigue results will depend on the characteristics of the full loading cycle (loading-holding-unloading) history. This investigation also identifies the shape memory/pseudo-elasticity of the TiNi layer on $\mathrm{Si}$ substrate under these loading conditions with two different shape indenters. The interfacial adhesion failure is also performed using three-dimensional finite-element analysis (FEA) of stress distribution during indentation contact of the TiN top layer and underlying TiNi layer on Si substrate.

\section{Experimental and Simulation Work}

\section{Test Specimen Preparation and Characterisation}

TiNi films of $3.5 \mu \mathrm{m}$ thickness were prepared on a $450-\mu \mathrm{m}$ thick (100) silicon substrate by co-sputtering a Ti0.5Ni0.5 target with an RF power density of $8.8 \mathrm{~W} / \mathrm{cm}^{2}$ and a Ti target at a DC power density of $0.3 \mathrm{~W} / \mathrm{cm}^{2}$. During deposition, the silicon wafer was heated to $450{ }^{\circ} \mathrm{C}$ for in situ crystallisation. Following deposition of the TiNi film without breaking vacuum, a layer of $\sim 200$-nm-thick TiN was prepared by sputtering the $\mathrm{Ti}$ target at a $\mathrm{DC}$ power density of $4.4 \mathrm{~W} / \mathrm{cm}^{2}$ for $30 \mathrm{~min}$ with $\mathrm{Ar} / \mathrm{N}_{2}$ gas ratio of 1/1. The argon pressure was 1.0 mTorr.

The $\mathrm{Ti} / \mathrm{Ni}$ ratio in the film was determined as $49.8 / 50.2$ by energy dispersive X-ray spectroscopy (EDX). Martensitic transformation behaviour was analysed using a Philips PW3719 XRD at different temperatures from $20{ }^{\circ} \mathrm{C}$ to $75^{\circ} \mathrm{C}$. The phase transformation temperatures of the TiN/ TiNi film were obtained using a differential scanning calorimetry (DSC, Perkin Elmer) at a heating/cooling rate of $5{ }^{\circ} \mathrm{C} / \mathrm{min}$. Surface roughness was measured using an atomic force microscope (AFM, Nanosurf ${ }^{\circledR}$ Nanite, SPM S50, Liestal, Switzerland) with a scan range of $5 \times 5 \mu \mathrm{m}^{2}$. The obtained roughness value, $R_{\mathrm{a}}$, from AFM analysis was approximately $30-40 \mathrm{~nm}$, indicating a very smooth film surface.

$\mathrm{X}$-ray photoelectron spectroscopy (XPS) analysis was performed on film surface using a Kratos-Axis spectrometer with monochromatic $\mathrm{Al} \mathrm{K} \alpha(1486.71 \mathrm{eV}) \mathrm{X}$-ray radiation and hemispherical analyser. The survey spectra in the 
range of $0-1100 \mathrm{eV}$ were recorded in $1 \mathrm{eV}$ steps for each sample, followed by high-resolution spectra over different elemental peaks in $0.1 \mathrm{eV}$ steps, from which the detailed composition was calculated. Curve fitting was performed after a Shirley background subtraction by a nonlinear least square fitting using a mixed Gauss/Lorentz function. To do a depth analysis, Ar ion bombardment was carried out using a differential pumping ion gun with an accelerating voltage of $5 \mathrm{keV}$ and a gas pressure of $10^{-7}$ mTorr. The bombardment was performed at an angle of incidence with respect to the surface normal to $45^{\circ}$. The ion gun flux was about $10^{14}$ ions $\mathrm{cm}^{-2} \mathrm{~s}^{-1}$.

\section{Single-Loading Cycle Nanoindentation Testing}

Nanomechanical measurement (hardness, $H$, and elastic modulus of specimen surface, $E_{\mathrm{s}}$ ) at a normal load of 100 $\mu \mathrm{N}$ was characterised using a NanoTest ${ }^{\mathrm{TM}}$ system (Micro Materials Ltd., UK) by employing a Berkovich diamond indenter. The indentation procedures were programmed as three segments of a trapezoidal shape. For the first segment, the load was increased to a maximum value with a loading rate of $2 \mathrm{mN} / \mathrm{s}$, following by a 5-s holding segment (second one) at the maximum load. For the third segment, the indenter tip was unloaded from the sample with an unloading rate of $2 \mathrm{mN} / \mathrm{s}$. The area function for the Berkovich indenter was calibrated on a standard fused silica reference sample. The force-displacement $(P-h)$ profiles were analysed per the Oliver and Pharr method to determine the hardness and elastic modulus [37]. For the calculation of the thin-film elastic modulus $\left(E_{\mathrm{s}}\right)$, the elastic modulus of the diamond indenter $\left(E_{\mathrm{i}}\right)$ and Poisson's ratio of the diamond indenter $\left(v_{\mathrm{i}}\right)$ were used as $1140 \mathrm{GPa}$ and 0.07 , respectively, and the Poisson's ratio of the top layer of the TiN thin film $\left(v_{\mathrm{s}}\right)$ was 0.22 . Post-indentation residual craters were mapped using an atomic force microscope (AFM, Nanosurf $^{\circledR}$ Nanite, SPM S50, Liestal, Switzerland) at a scan rate of $1 \mathrm{~Hz}$.

\section{Multiple-Loading Cycle Nanoindentation Testing}

A multiple-loading cyclic nanoindentation with a trapezoidal function was programmed into three segments which are the same with the above-mentioned single-cycle measurement. The first segment comprised a peak loading in $10 \mathrm{~s}$ followed by a $5 \mathrm{~s}$ holding segment at the peak load. The third segment retrieved the indenter tip from the sample in $10 \mathrm{~s}$ to the $30 \%$ of the test load before reloading for the next cycle. The applied loads were $0.1-1,1-10$, 10-100, and 100-500 $\mathrm{mN}$. Each test was conducted for a total of 10 incremental multiple-loading cycles using two types of indenters (Berkovich and conical). The conical indenter with $10 \mu \mathrm{m}$ tip radius was used. Two different indenter types were used to obtain different stress concentrations and generate cracking or deformation in the film. Five repeated tests were done for each load range to ensure repeatability of the experimental data. An equal displacement approach [38] was used to keep the loading force larger than the unloading force (i.e. $P_{\mathrm{L}}>P_{\mathrm{U}}$ ). Posttest craters were mapped using the above-mentioned AFM at a scan rate of $1 \mathrm{~Hz}$.

\section{Nano-Impact (Fatigue) Testing}

Nano-impact (localised contact fatigue) experiments of the thin film were conducted using the aforementioned NanoTest $^{\mathrm{TM}}$ system and both Berkovich and conical indenters with four different impact forces (i.e. 0.5, 1, 10 and 100 $\mathrm{mN}$ ) for 1000 impact cycles at each load. The loading and unloading cycles for the nano-impact tests involved a linear loading of the specimen to a full load in one second and then a full unloading in another second with a zero-hold time at the peak load (each run with total test time of 2000s). A total of five repeated tests for each indenter shape were conducted at each load. The evolution of surface impact response was recorded in situ by monitoring the changes in the positions of the indenter (depth vs. time). This technique was adapted to understand the mechanisms of nano-impact (low-cycle fatigue) failure [32, 33] of the constraint TiN/TiNi bilayer which could be different from those of free-standing films due to constraint effect of the substrate, stress gradient effect and existence of residual stress. The failure was defined as a sudden change in depth amplitude with time or number of impacts. All the above nanomechanical tests and measurements were done in the instrument chamber at an ambient temperature of $23{ }^{\circ} \mathrm{C}$.

\section{Finite-Element Simulation of Indentation Contact}

This simulation section by no mean presents constitutive model for simulating the rate-dependent pseudo-elastic shape memory alloys, but presents a finite-element (FE) elastic simulation to understand the contact mechanics of indentation in a residual stress free (pre-existing) bilayer coating-substrate system. This indentation loading has been performed to investigate the location of subsurface maximum stress near the interface (and not the shape memory features) which can influence film failure. Because of their complex nature and film properties which vary with depth and materials of varying toughness, FE simulations of indentation testing (under Berkovich and conical indenters; with $10 \mu \mathrm{m}$ tip radius for conical indenter) of TiN $(200 \mathrm{~nm})$ on TiNi $(3.5 \mu \mathrm{m})$ on 7.5 - $\mu \mathrm{m}$-thick Si substrates can provide valuable information to ascertain the dominant stress fields. 
The FE simulations were conducted using ANSYS Parametric Design Language (APDL) program. All the materials are assumed to have elastic behaviour. The symmetrical nature of the indentation has been considered during the creation of the models, and thus, in the case of Berkovich indentation, only half of the entire model was considered with the half plane acting as the plane of symmetry. Similarly, one quarter of the geometry has been modelled in conical indentation as there are two symmetry planes in this case. The elastic modulus and Poisson's ratio of the $\mathrm{Si}$ substrate were considered as $150 \mathrm{GPa}$ and 0.17 [39], respectively. The corresponding values for the TiNi coating were taken as $55 \mathrm{GPa}$ and 0.33 , respectively [39], and for the TiN coating, they were $132 \mathrm{GPa}$ and 0.22 [39], respectively.

The interfaces between the Si substrate and TiNi coating and those between the TiNi coating and TiN coating have been assumed to be perfectly bonded. All the geometrical entities except the Berkovich indenter have been meshed using Solid185 hexahedral elements for maximum accuracy of the results. The Berkovich indenter has been modelled with Solid185 tetragonal elements as the hexahedral elements cannot be used in this case. The contact between the indenter and the TiN film surface has been modelled using a contact pair with contact 174 and target 170 elements.

These elements were used to model the contact between the indenter and target TiN surfaces as a series of high stiffness springs which transmit the load between the two. The contact stiffness has been chosen to be sufficiently high so as not to allow any penetration between the two surfaces but still ensuring faster convergence of the solution. The number of elements and nodes used in the case of the Berkovich indentation were 72736 and 82621, respectively (excluding the contact and target elements), which gave accurate results. Similarly, in the case of conical indentation, the number of elements and nodes were 56128 and 64908, respectively (excluding the contact and target elements). The mesh density has been increased at the expected high stress concentration zone. For the FE simulation, the maximum load applied was $500 \mathrm{mN}$. The vonMises stress and strain criteria were used in identifying the failure locations.

\section{Results and Discussion}

\section{Thin-Film Characterisation}

Results from the DSC shown in Fig. 1a confirmed the occurrence of the martensitic transformations during heating and cooling and that a thin layer of TiN did not change the phase transformation behaviour [39]. Transformation from martensite to austenite was observed during heating, whereas a two-stage transformation among austenite, R-phase and martensite was found during cooling. During heating, the austenite start and finish temperatures are $57{ }^{\circ} \mathrm{C}$ and $68^{\circ} \mathrm{C}$, respectively. During cooling, the R-phase start and finish temperatures are $39{ }^{\circ} \mathrm{C}$ and $32{ }^{\circ} \mathrm{C}$, and the martensitic transformation start and finish temperatures are $25{ }^{\circ} \mathrm{C}$ and $16{ }^{\circ} \mathrm{C}$, respectively. Clearly, the transformation finishing temperature from R-phase to martensite phase is well below the room temperatures of $23{ }^{\circ} \mathrm{C}$. XRD analysis results of the graded film at different temperatures are plotted in Fig. 1b. It reveals the existence of a mixture of martensite and R-phase (based on DSC results) as well as TiN phases at the room temperature of $23{ }^{\circ} \mathrm{C}$. With the increasing temperature, the remaining martensite gradually changes to austenite (cubic) during heating, and vice versa during cooling, demonstrating the occurrence of martensitic transformation.

The composite depth profiles of TiN/TiNi films obtained from XPS analysis are shown in Fig. 1c. As expected, Ti and $\mathrm{N}$ elements dominate the surface of the sample. Inspection of the profiles shows three different regions. The first region is near the surface, and is characterised by Cand O-contaminated layer $(<20 \mathrm{~nm}$ thick $)$. Since the samples were exposed to atmosphere prior to measurement, the surface contaminants, i.e. $\mathrm{O}$ and $\mathrm{C}$, were introduced due to the adsorption. With ion bombardment, $\mathrm{C}$ and $\mathrm{O}$ can be removed quickly. The second region presents the composition of TiN layer in which the atomic ratio of Ti over $\mathrm{N}$ is about 1.2-1.5:1. It should be noted that XPS has a better sensitivity for determining low concentrations of nitrogen, oxygen and carbon elements, but underestimates their amounts at higher concentrations [40-42]. During sputtering process, effects such as preferential sputtering of different atomic species may take place. Argon ion sputtering was found to be selective for the TiN, favouring a slight Tienriched results for the surface region [43]. Therefore, in the TiN layer, the nitrogen concentration could be slightly higher than the XPS determined values. The third region is a 200-nm-thick intermediate layer in which TiN phase is gradually changed to TiNi phase (from a depth of about $150-320 \mathrm{~nm})$. Due to the high temperature during deposition, there is significant inter-diffusion of $\mathrm{Ti}, \mathrm{N}$ and $\mathrm{Ni}$ elements in this intermediate layer. Nitrogen was detected at a depth of $\sim 300 \mathrm{~nm}$ into the TiNi film. Surface of TiNcoated TiNi films is nickel free. Traces of Ni element can be detected only $150 \mathrm{~nm}$ below the surface. It is thus expected that this TiN layer could act as a nickel diffusion barrier. $\mathrm{Ni}$ increases from zero to TiNi composition and $\mathrm{N}$ decreases to trace amount, while $\mathrm{Ti}$ gradually reduces to TiNi composition.

Figure $1 \mathrm{~d}$ shows $\mathrm{Ti} 2 \mathrm{p}$ spectra of $\mathrm{TiN}$ layer and then the TiNi film layer, both showing the $\mathrm{Ti} 2 \mathrm{p}^{1 / 2}$ and $\mathrm{Ti} 2 \mathrm{p}^{3 / 2}$ 

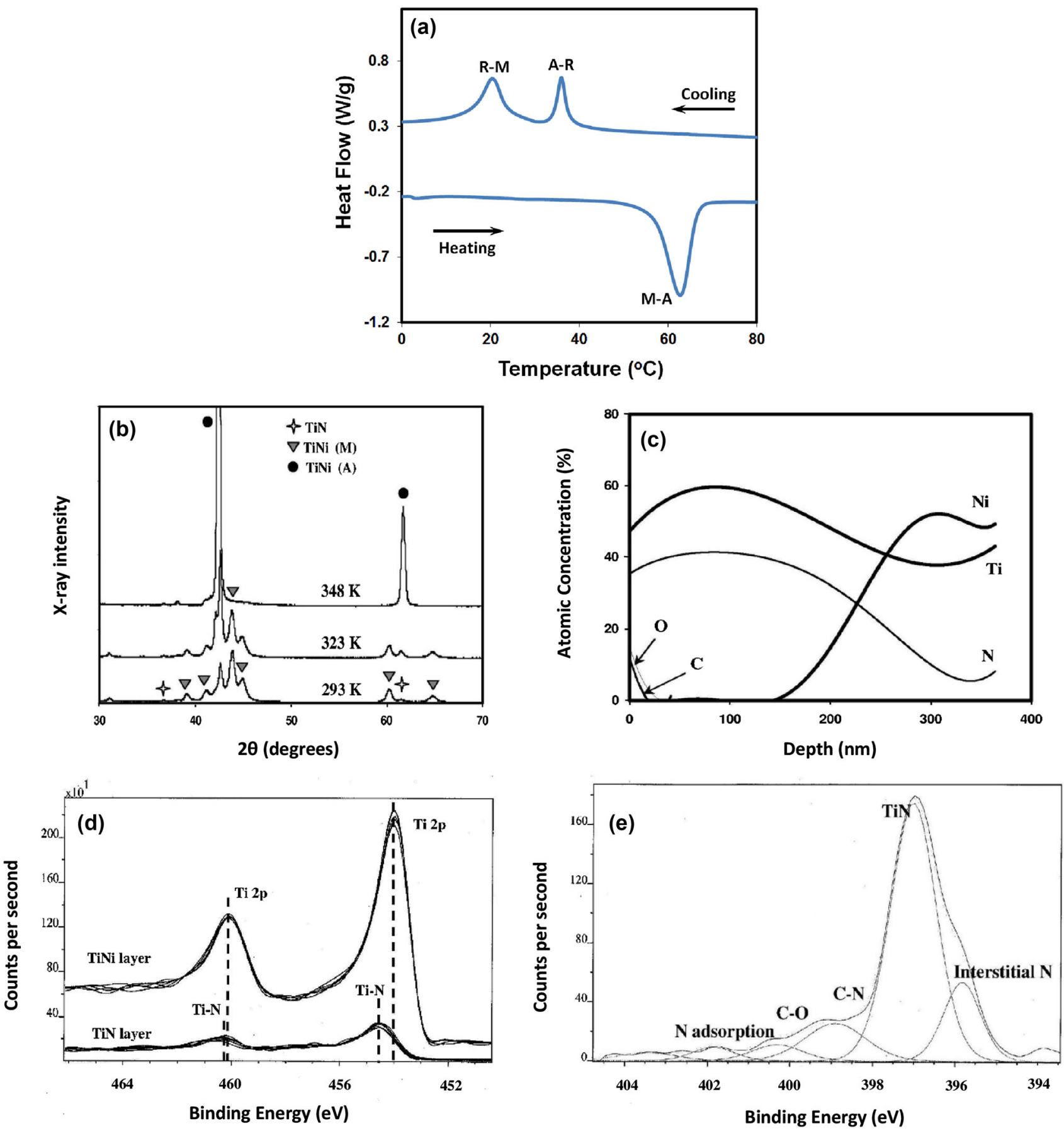

Fig. 1 Characterisation results: a DSC result of the TiN-coated TiNi films, indicating transformation from martensite to austenite during heating (M-A); and transformations from austenite to R-phase (A-R) and R-phase to martensite (R-M); b XRD showing crystalline phases changing with temperature, and XPS analysis showing, $\mathbf{c}$ composition

peaks. These two peaks can be deconvoluted into subpeaks. On the TiN layer, the dominant peak is $\mathrm{Ti}^{+}$peak, with a broad range of combined peaks of Ti-X (consisting of stoichiometric and non-stoichiometric TiN phases, titanium oxide, titanium oxy-nitride). As shown in Fig. 1d, the

changes with the increase of depth for TiN-coated TiNi film obtained from XPS analysis, $\mathbf{d}$ comparison between Ti $2 p$ peaks in TiNi and TiN layer (in arbitrary units), and e N 1s spectrum on surface layer of TiN-TiNi graded coating

detailed deconvolution of $\mathrm{Ti}$ components in the TiN surface layer is quite difficult because there could be overlapping among different components [30, 40-44]. However, the dominant $\mathrm{Ti} 2 \mathrm{p}^{1 / 2}$ and $\mathrm{Ti} 2 \mathrm{p}^{3 / 2}$ peaks in the TiNi layer are linked with metallic Ti states in the TiNi 
phase, and the binding-energy values are slightly lower than those of the Ti $2 p$ peaks in the TiNi phase. This is mainly due to the charge transfer caused by the Ti-N bond formation. For the Ti 2 p peaks in the TiNi layer, there is also a broad range of combined peaks of Ti-X (consisting of stoichiometric and non-stoichiometric TiOx phases).

Figure 1e shows $\mathrm{N}$ 1s spectrum in the TiN layer of TiNTiNi graded film. The strongest peak is attributed to N-Ti. There are two peak components related to $\mathrm{N}-\mathrm{O}$ and $\mathrm{N}-\mathrm{C}$ bondings. As shown in Fig. 1e, the presence of small peak at around $402 \mathrm{eV}$ is due to chemisorbed nitrogen [30]. The fact that a short-time sputtering eradicated these small peaks indicates that they are from surface contaminants. There is a peak at $395.7 \mathrm{eV}$ which can be attributed to the binding energy of nitrogen atoms in interstitial tetrahedral position in TiN lattice [41]. The ratio between on-site $\mathrm{N}$ in TiN lattice and interstitial $\mathrm{N}$ was found to vary from $6 / 1$ to $7 / 1$, indicating most nitrogen atoms are in the TiN lattice. There are certain amounts of interstitial nitrogen existing persistently in the TiN layer.

\section{Single-Loading Cycle Nanoindentation}

Figure 2a shows the indentation curves during loading/ unloading processes using the Berkovich indenter with an indentation load of $100 \mu \mathrm{N}$ load. From the experimental nanoindentation results, the hardness $(H)$ and elastic modulus $\left(E_{\mathrm{s}}\right)$ of the surface layer at $100 \mu \mathrm{N}$ load were obtained as $7.8 \pm 4$, and $83 \pm 42 \mathrm{GPa}$, respectively (with average maximum indentation depth of $32 \pm 6 \mathrm{~nm}$ ). A nanoindentation load of $200 \mathrm{mN}$ was also chosen (single run, Fig. 2b), which corresponds to a relative indentation depth (RID) of 0.4 using the combined film thicknesses $(3700 \mathrm{~nm})$. The measured hardness $(H)$ and elastic modulus $\left(E_{\mathrm{s}}\right)$ were 5.05 and $116 \mathrm{GPa}$, respectively (with a maximum indentation depth of $1453 \mathrm{~nm}$ ). Figure 2c shows the corresponding AFM image (inset: an optical microscope image without scale marker). Due to the large indentation stress, significant plastic deformations occur in both the TiN and NiTi layers, and thus, the recovery ratio is not very high. Figure $2 \mathrm{c}$ also shows the occurrence of a moderate fracture and film delamination around the indentation edge possibly due to cohesive and adhesive failures.

As shown in Fig. 2(a), it should be noted that the loading curve $(\mathrm{OA})$ and the holding curve $(\mathrm{AB})$ are forward progressing during each indentation cycle, and the unloading curve (BC) is backward progressing. This type of nanoindentation cycle profile is typical in nanoindentation testing. Hereafter, it is defined as forward depth deviation (FDD) (Faisal et al. [45, 46]. In this case, using the 'equal displacement approach' [38], the loading force in $P-h$ profile is larger than the unloading force (i.e. $P_{\mathrm{L}}>P_{\mathrm{U}}$ ). At such a low
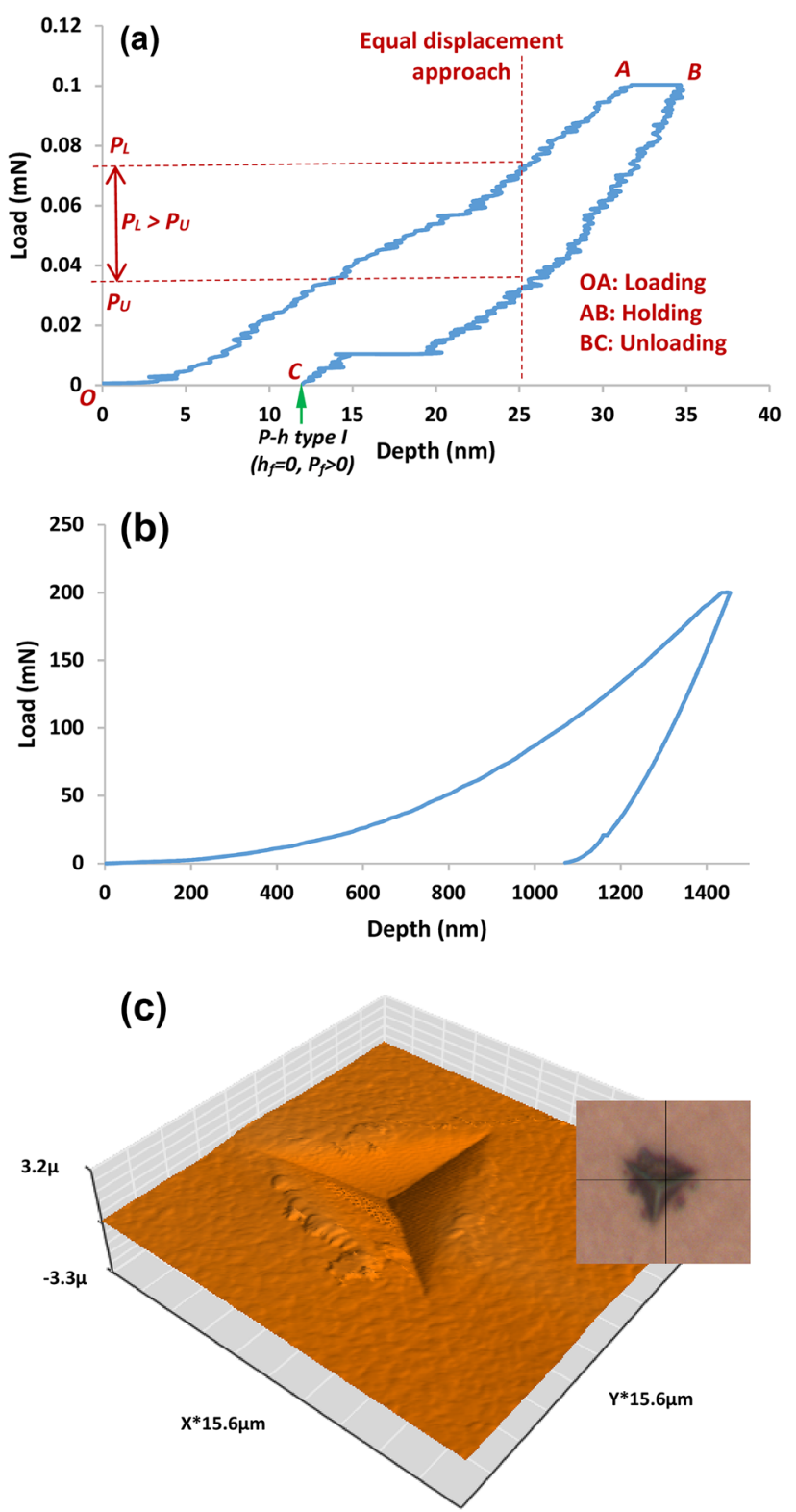

Fig. 2 Typical single-cycle nanoindentation testing (Berkovich indenter): a $100 \mu \mathrm{N}$ load, b $200 \mathrm{mN}$, and c corresponding AFM image (inset plan view optical microscope image at $\times 40$ magnification) at $200 \mathrm{mN}$ load. Forward depth deviation, $P_{\mathrm{L}}>P_{\mathrm{U}}$, where $P_{\mathrm{L}}$ and $P_{\mathrm{U}}$ are loading and unloading forces, respectively, at equal displacement

load (e.g. $100 \mu$ N, Fig. 2a), the tip of the Berkovich indenter is in contact with both the top TiN layer as well as TiNi layer, and the deformation of the composite layer is a combination of elastic/plastic deformation of TiN layer as well as the pseudo-elastic and martensitic detwining of the underlying TiNi layer (as the phase is a mixture of R-phase and martensite). This results in a significant overall recovery ratio in the $P-h$ unloading profile (post-indentation AFM image could not be obtained, as there was no apparent indentation mark observed). 
It is known that the evaluations of hardness $(H)$ and elastic modulus $\left(E_{\mathrm{s}}\right)$ of the thin film require careful assessment of the test parameters. This is because such measurements may sometime represent a combined property of the top layer film (TiN), sub-layer thin film (TiNi) and the Si substrate rather than the film alone. A general rule of thumb that the indentation depth should be $1 / 10$ of the film thickness (RID $=0.1$ ) is widely applied (e.g. Faisal et al. [45, 47] to avoid plastic deformation of the substrate. In the current investigation, the nanoindentation tests were done in a force control mode with a fixed maximum load of $100 \mu \mathrm{N}$, which corresponds to an RID of 0.16 (if only the top layer TiN film thickness of $200 \mathrm{~nm}$ is considered) and 0.01 (if the combined TiN top layer film thickness of $200 \mathrm{~nm}$ and 3500-nm second layer was considered). It is important to note that these rules are often not practical for film thickness values below $1 \mu \mathrm{m}$ (as discussed in Faisal et al. [32, 33, 45, 46]. The values of hardness $(7.8 \pm 4 \mathrm{GPa})$ and modulus $(83 \pm 42 \mathrm{GPa})$ measured in this investigation are, however, much lower than those observed for TiN coatings of similar thicknesses deposited by unbalanced magnetron sputtering [48], where typical hardness and modulus values were $22.8 \pm 3.4$, and $276 \pm 41 \mathrm{GPa}$, respectively. The values recorded here for the TiN film is closer to those of TiNi coatings which generally have values from 7.2 to 9.2 and 113 to $132 \mathrm{GPa}$, respectively [49]. Hence, the values of hardness and modulus measured are actually a combined one from the graded layer of TiN/TiNi film response.

\section{Multiple-Loading Cycle Nanoindentation}

\section{Berkovich Indenter}

Figure 3 shows the $P-h$ profiles of multiple-load cycle Berkovich nanoindentation (from Fig. 3a(i)-d(i)) and their corresponding AFM images of indented marks (from Fig. 3a(ii)-d(ii)) obtained at various load ranges of $0.1-1$, 1-10, 10-100 and 100-500 $\mathrm{mN}$.

As shown in Fig. 3a, b(i) for load range (0.1-1, 1-10 $\mathrm{mN}$ ), the multiple-load cycle nanoindentation profiles indicate maximum displacements in each cycle during indenter loading, due to the hysteresis of forward and backward loading depths, whereas in the $P-h$ profiles in Fig. 3c, d(i) for load range (10-100, 100-500 mN), the profiles indicate maximum displacements in each cycle during indenter loading due to the hysteresis of forward loading depth, thus showing a clear forward depth deviation. A small pseudo-elastic recovery can be observed in each cycle of the $P-h$ profiles, which causes hysteresis loops as shown in the inset of Fig. 3d(i) to appear in the loading and unloading profiles, for each repeated cycle at the studied load range (more dominant for $0.1-1$ and $1-10$, less dominant for 10-100 and 100-500 mN).

In Fig. 3a(ii), at such a low load range $(0.1-1 \mathrm{mN})$, due to the pseudo-elasticity and elastic deformation effects from both the $\mathrm{TiNi}$ and $\mathrm{TiN}$ layers, shape is almost recovered, as observed for all runs. The final cycle coordinate, $C$ (as defined in Fig. 2a), appears to be located at $h_{\mathrm{f}}>0, P_{\mathrm{f}}>0$ (where $h_{\mathrm{f}}$ is the final displacement and $P_{\mathrm{f}}$ is the corresponding residual forces). In Fig. 3b(ii) for the load range $(1-10 \mathrm{mN})$, due to a combined pseudo-elasticity and elastic-plastic deformation of the film (martensite detwinning as well under this large pressure), shape is partially recovered, as observed for all runs, and the final cycle coordinate, $C$, is located at $\left(h_{\mathrm{f}}=0, P_{\mathrm{f}}>0\right)$. In Fig. 3c, d(ii) for the large load range (10-100, 100-500 $\mathrm{mN}$ ), the indentation shapes are partially recovered, as observed for all runs, and the final cycle coordinate, $C$, is located at $\left(h_{\mathrm{f}}=0, P_{\mathrm{f}}>0\right)$. The corresponding AFM images show residual indentation impressions after the final cycle, including film failure around the indentation edge (Fig. 3d(ii)). It should be noted that significant indenter penetration has occurred immediately with the onset of indentation using the Berkovich indenter. This is well beyond the top TiN layer thickness of $200 \mathrm{~nm}$, i.e. after cycle 4 at the load range of $1-10 \mathrm{mN}$ as shown in Fig. 3b(i), and during cycle 1 for the load ranges 10-100 and 100-500 $\mathrm{mN}$ as shown in Fig. 3c(i) and d(i), respectively.

Multiple-load cycle nanoindentation experiments using the Berkovich indenter indicated that the deformation of the composite film (i.e. TiN on TiNi on Si substrate) can occur for the lowest load range $(0.1-1 \mathrm{mN})$ to mid-level load range $(1-10,10-100 \mathrm{mN})$. However, moderate fracture (possibly both cohesive and adhesive, including film delamination around the indentation edge) can occur at the highest load range (100-500 mN) (e.g. Fig. 3d(ii)), observed for each of the five repeats. However, in all these examples, the AFM images of indented surface did not show significant film and substrate failure. At the lowest load range $(0.1-1 \mathrm{mN})$, the indentation measurement mainly includes thin film, but at higher load range (1-10, $10-100,100-500 \mathrm{mN}$ ), the measured property represents a combination of film/substrate properties.

\section{Conical Indenter}

Figure 4 shows the $P-h$ profiles of multiple-cycle loading using the conical nanoindenter (from Fig. $4 a(i)-d(i)$ ) and their corresponding AFM images of indented marks (from Fig. 4a(ii) to Fig. 4d(ii)) obtained at 0.1-1, 1-10, 10-100, and $100-500 \mathrm{mN}$ loads.

The multiple-load cycle conical nanoindentation $P$ $h$ profiles (Fig. 4(i, ii)) indicate broadly similar behaviour 
(i) P-h profile

(a) $0.1-1 \mathrm{mN}$

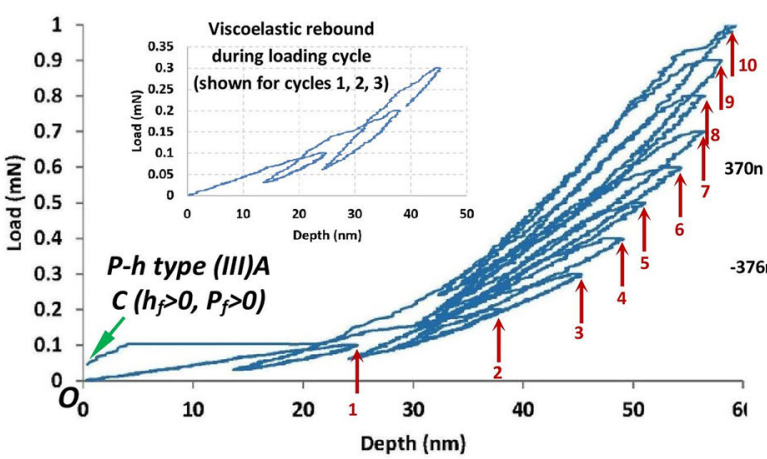

(b) $1-10 \mathrm{mN}$

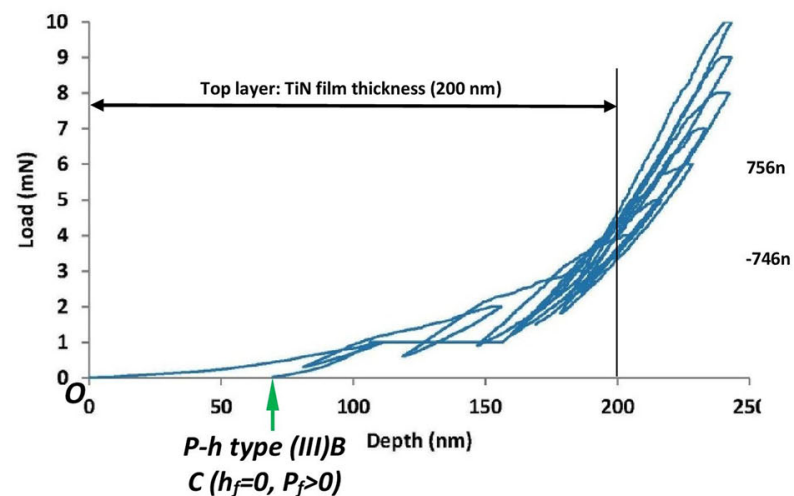

(c) $10-100 \mathrm{mN}$

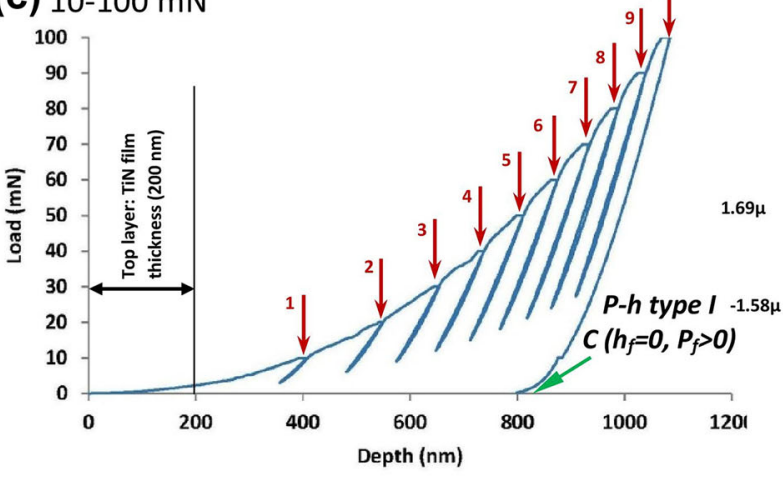

(d) $100-500 \mathrm{mN}$

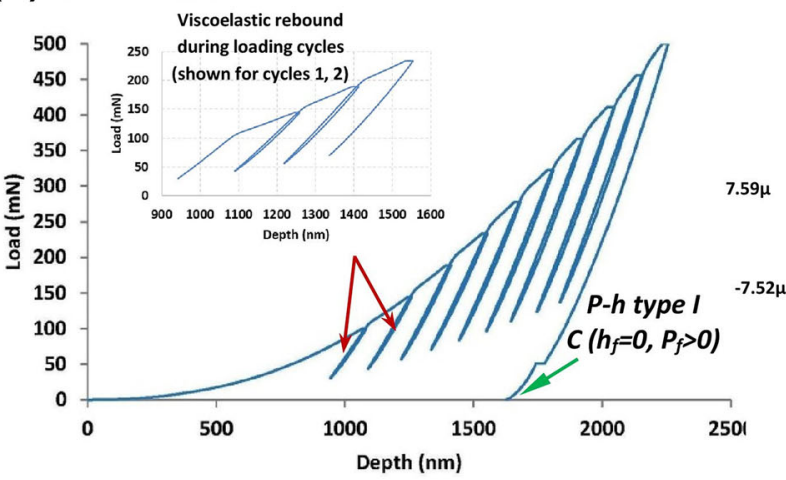

(ii) AFM image
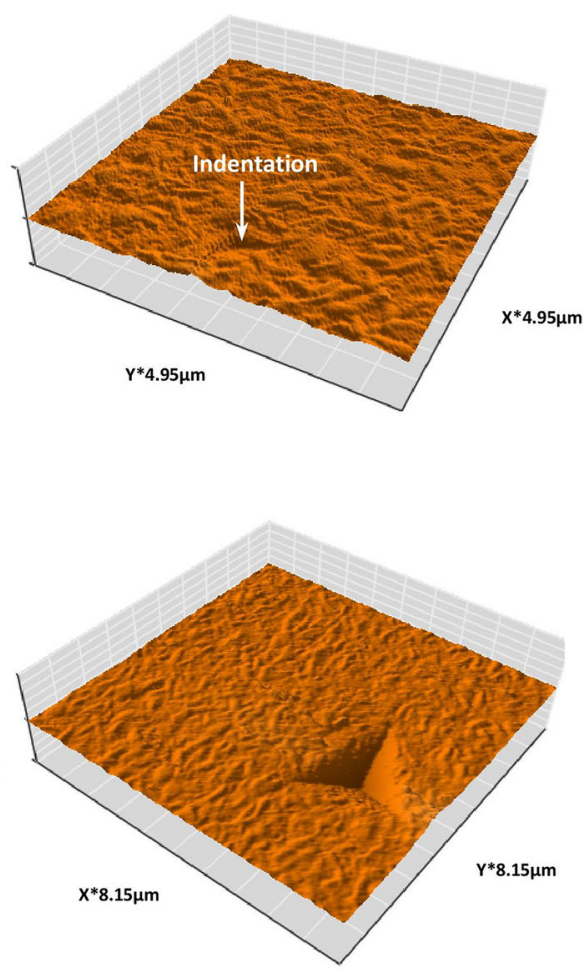

$8.15 \mu \mathrm{m}$

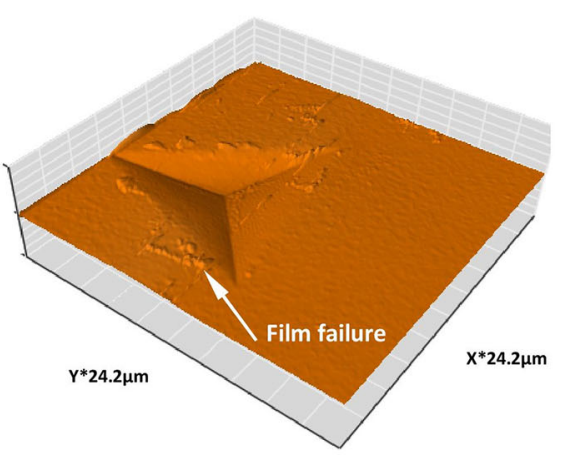


4Fig. 3 Typical multiple-load cycle nanoindentation testing (Berkovich indenter). Note: upward arrows in $\mathbf{a}(i)$ indicate maximum displacement in each cycles during indenter loading (hysteresis-based forward and backward depth deviation starts); downward arrows in c $(i)$ indicate maximum displacement in each cycles during indenter loading (forward depth deviation starts)

to Berkovich indenter results (Fig. 3(i)) at different depth magnitudes. In Fig. 4b, c, d(i), a small pseudo-elastic recovery can be observed in each cycle of the $P-h$ profiles, which causes hysteresis loops (shown in inbox, Fig. 4b(i)) to appear in the loading and unloading profiles, observed for each repeat cycles at the studied load range (more dominant for $1-10 \mathrm{mN}$, less dominant for $10-100$ and $100-500 \mathrm{mN})$. Multiple-load cycle nanoindentation experiments using the conical indenter indicated that the deformation of the combined film (i.e. TiN on TiNi on $\mathrm{Si}$ substrate) can occur at a load range of $1-10 \mathrm{mN}$, observed for each of the five repeats. However, moderate fracture (clearly seen as pop-ins in Fig. 4c(i), possibly due to both cohesive and adhesive failures, including film delamination and substrate fracture) can occur at a higher load range $(10-100 \mathrm{mN})$, observed for just one of the five repeats. No such pop-ins were observed during any repeats for the highest load range (100-500 mN), as shown in Fig. 4d(i). However, in all these cases, the AFM images are not indicative of significant film and substrate failures.

\section{Nano-Impact (Fatigue)—Berkovich and Conical Indenters}

Nano-impact (fatigue) experiments of thin film were conducted using both the Berkovich and conical indenters with four different impact forces $(0.5,1,10$ and $100 \mathrm{mN}$; and 1000 impact cycles for each load). Figures 5a(i) and a(ii) show typical depth versus time curves of nano-impact obtained at a load of $100 \mathrm{mN}$ under Berkovich and conical indenters. Figures $5 b(i)$ and $b(i i)$ show the corresponding AFM images of impact marks (showing some wear around impact), and Fig. 5c(i) and c(ii) show cross-sectional morphologies of the centre of the impact craters. During this fatigue test, it was noted that each hysteresis curve (depth vs. time) was forward progressing during an early stage of impact and then the increment was linearly increased for many cycles at $0.5 \mathrm{mN}$ load. At the moderate loads ( 1 and $10 \mathrm{mN})$, each hysteresis curve was forward progressing during an early stage of impact, reached its maximum penetration, and then the depth decreased (backward depth deviation) linearly for much of the cycles. Backward depth deviation for Berkovich indenter (e.g. Fig. 5a(i)) indicated a sudden film delamination (not observed for conical indenter) for two runs (out of five) at $100 \mathrm{mN}$ load between 200 and 550 impact cycles.
Table 1 summarises the different types of depth-time profiles of nano-impact (fatigue) and Fig. 6 presents the schematics (simple hypothesis) of thin-film behaviour during nano-impact (fatigue) under Berkovich (or conical) indenter, revealing the different types of depth deviations. The backward depth deviation at the final impact cycle indicates two types of deviations (Types I and II). Type I indicate that the final impact depth (at the 1000th impacts) is below zero, $h_{\mathrm{f}}<0$; however, Type II indicates that the final impact depth is above zero, $h_{\mathrm{f}}>0$ (Fig. 6). As observed from AFM images (e.g. Fig. 5(b)), no surface cracking and delamination of the film occurred at this load, but some amount of wear around the impact can be observed. From Table 1, the co-ordinates of the depth at the final 1000th impact $\left(h_{\mathrm{f}}\right)$ at all four loads can be below zero (backward depth deviation of Type I), above zero (forward depth deviation; or backward depth deviation of Type II) or equal to zero (no depth deviation).

The plastic zone around an impact zone can drive a lateral crack along a weak film/substrate interface, leading to film delamination. Residual stresses in the film can exaggerate the delamination by causing buckling of the film. The delamination is usually evident as the surface uplift around the impact, enabling indication of the crack size and calculation of interface toughness. As mentioned above, results of depth versus time curve indicate occurrence of both forward and backward depth deviations. For both the indenters, no cracking in the thin film was observed at the given AFM resolution. The interfacial delamination (buckling or surface uplift around the impact, as shown in Fig. 5b(i)) is associated with the distinct features in depth versus time curves (as shown in Fig. 5a(i)) indicating the backward depth deviation (at $100 \mathrm{mN}$ loads). This backward depth deviation has been previously investigated [47] in nano-impact (1000 impacts at $1 \mathrm{mN}$ load using NanoTest ${ }^{\mathrm{TM}}$ system) testing of 100-nm-thick DLC film. It has been indicated that the film delamination at the interface is possible without surface cracking and significant reduction in contact depth (i.e. backward depth deviation) (Ahmed et al. [50]. Also, the failure can start as a crack perpendicular to the film-substrate interface which is followed by film decohesion from the interface. It has also been observed during nano-impact (Zhang et al. [51] of other thin films (with interlayer of $15-50 \mathrm{~nm} \mathrm{Ni}$ or $\mathrm{Cr}$ prior to the deposition of $250 \mathrm{~nm}$ Pt-Ir films on binderless cemented carbide tools). Without the interlayer of $\mathrm{Ni}$ or $\mathrm{Cr}$, the indenter depth continued to increase dramatically as the repetitive impact test progressed, but the films with interlayer were more impact-resistant with the best impact resistance occurring in a Pt-Ir film with a $50 \mathrm{~nm} \mathrm{Cr}$ interlayer. However, in the current investigation, the large differences in mechanical properties of shape memory film (ductile and pseudo-elastic) with substrates, the film can 
(i) $P$-h profile

(a) $0.1-1 \mathrm{mN}$

P-h type IV

$C\left(h_{f}<0, P_{f}=P_{\max }\right)$

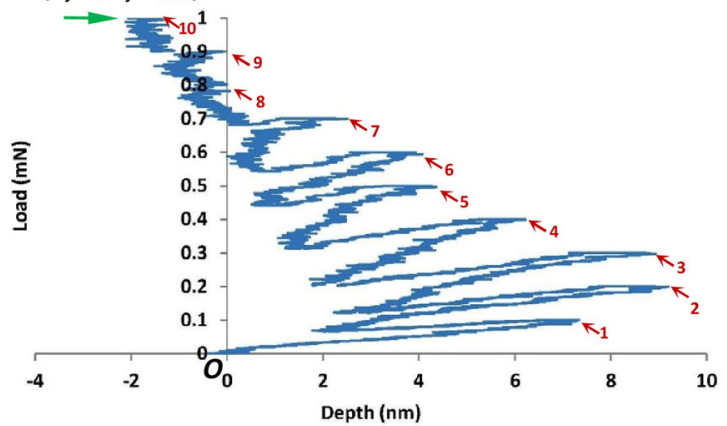

(b) $1-10 \mathrm{mN}$

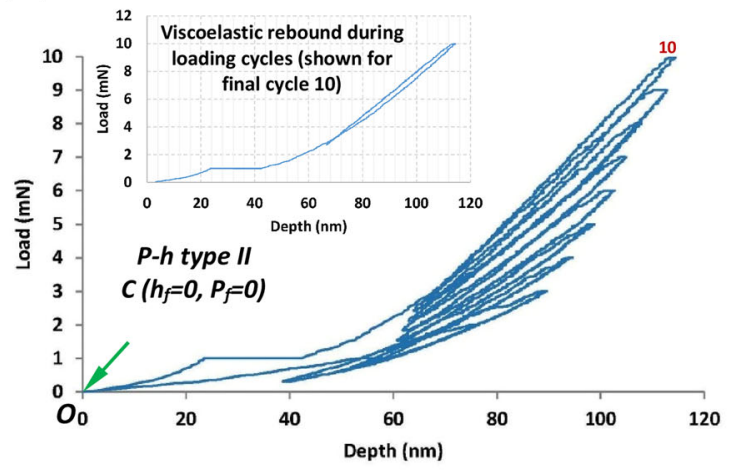

(c) $10-100 \mathrm{mN}$

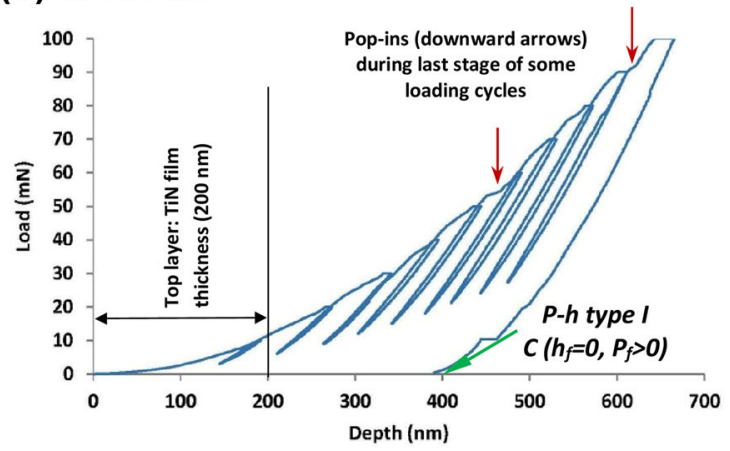

(d) $100-500 \mathrm{mN}$

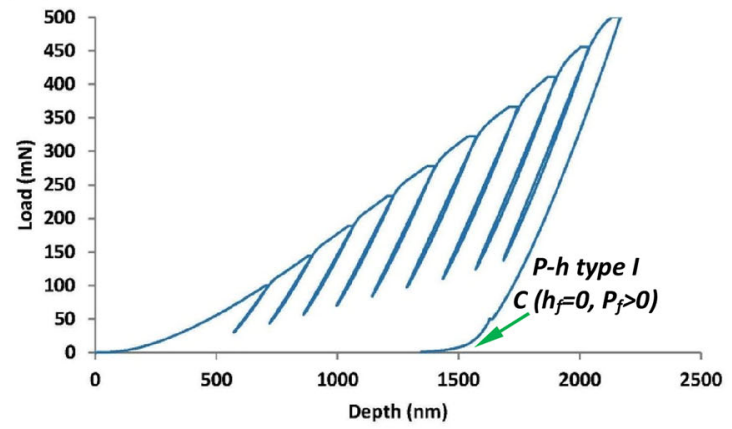

(ii) AFM image
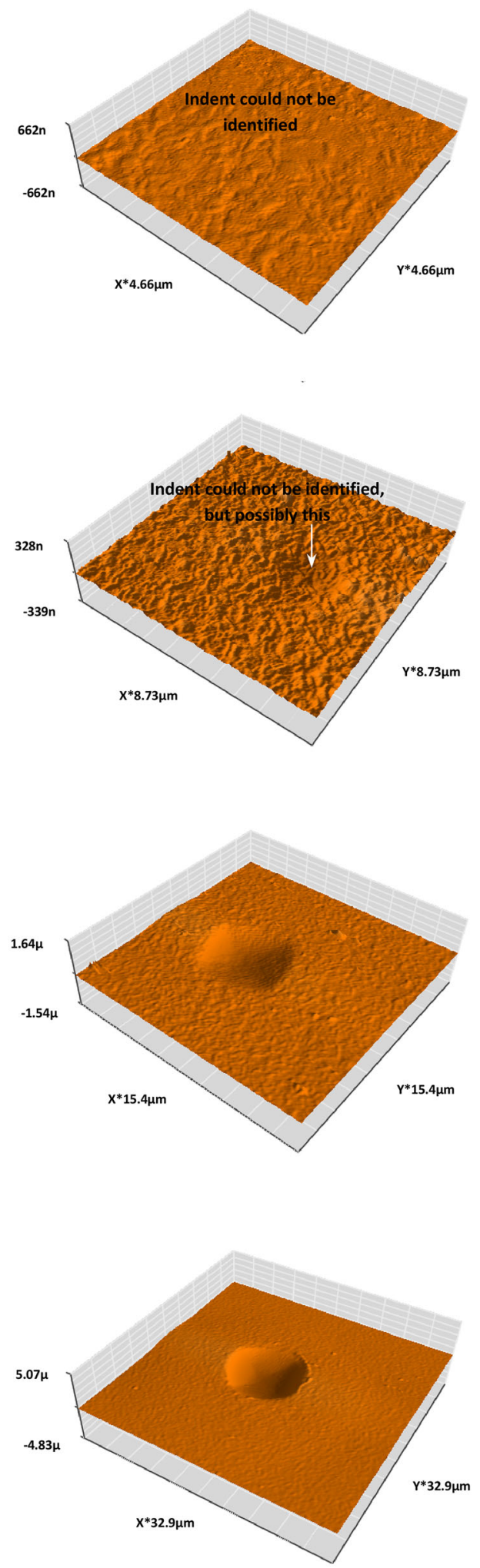
४Fig. 4 Typical multiple-load cycle nanoindentation testing (conical indenter). Note: upward arrows in a( $i$ ) indicate maximum displacement in each cycles during indenter loading (backward depth deviation starts)

deform significantly, but the substrate will not, thus there is fatigue-induced delamination or interfacial separation of TiNi films with substrates.

The depth-time curve for impact test shows a forward depth deviation during the early stage of impacts. For each impact, the absorbing energy will be different due to degradation of materials (indicated by changes in impact depths) in the contact and subsurface zones. After attaining a critical mismatch in the interfacial strain, the depth-time curve shows a backward depth deviation during the later stage of impacts. This is contrary to the expected behaviour where contact depth should increase with the number of impact cycles.

Based upon the observations discussed above related to depth-time, the film-substrate behaviours during nanoimpact (low-cycle fatigue) for both the indenters can be summarised as (a) forward depth increases leading to plastic deformation or delamination in the thin film and substrate, (b) mismatch in the interfacial strain leads to thin-film delamination or cracking from the substrate, and (c) depth decreases due to backward depth deviation (Type I or II) in the delaminated thin film. It is clear from the above discussion that the occurrence of backward depth deviation was load dependent. Due to the pseudo-elasticity of the TiNi film, the indented patterns can be partially recovered in such nanomechanical cyclic-loading process [31].

\section{Influences of Contact Load and Indenter Shape}

Contact stresses were introduced in the TiN/TiNi layered system by the means of load-controlled multiple-cycle nanoindentation. Berkovich and conical diamond indenters were pressed on to the sample at different loads. From the results shown in Fig. 3 (for Berkovich indenter) and Fig. 4 (for conical indenter), the thin film does not show significant surface failures (e.g. film cracking). However, deformation behaviours with different magnitudes can be observed for each load range investigated. The Berkovich indenter was expected to initiate cracking failure at the concentration zone of the high tensile (normal) stress thus leading to interfacial film delamination, in such nanomechanical loading process [31]. Under the Berkovich indenter when penetration depth is larger than the film thickness, the indenter penetrates much deeper into the substrate in each load cycle.

As shown in Fig. 3a, b(i) for the multiple-load cycle nanoindentation (Berkovich) profiles at $0.1-1$ and 1-10
$\mathrm{mN}$ load range, each loading cycle appears as hysteresisbased forward and backward depth deviations, indicating significant shape recovery strain (related to sub-layer TiNi due to pseudo-elastic effect) during each indentation cycles. Under the same load range (Fig. 4a, b(i)), the multiple-load cycle nanoindentation (conical) profiles has a much larger recovery strain, which have been widely reported [52]. At a higher load range (at 10-100 and $100-500 \mathrm{mN}$ ) under the Berkovich indenter in Fig. 3c,d(i), each loading cycle appears to have less hysteresis-based forward and backward depth deviations, indicating significant plastic deformation during each indentation cycle. Under the same load range (Fig. 4c, d(i)), the multiple-load cycle nanoindentation (conical) profiles will cause severe deformation, the film could lose the properties of pseudoelasticity. It is important to note that the Berkovich indentation $P-h$ profile features for higher load range (at 10-100 and 100-500 mN, Fig. 3c, d(i)) are less distinguishable (i.e. not much different) compared with the conical indentation $P-h$ profile features (Fig. $4 \mathrm{c}, \mathrm{d}(\mathrm{i})$ )), except the depth of indenter penetration (lower for conical indenter). The sharpness of the indenter (Berkovich) generally produces enhanced stresses (i.e. stress concentrations) and strains around the contact compared with relatively round-shaped indenter (conical). This can be useful in producing cracks around indentation impressions in brittle thin films (e.g. diamond-like carbon (Ahmed et al. [50], Faisal et al. [45-47, 53]). However, in the current investigation, the TiN/TiNi graded system appears to have significant resistance to apparent cracking due to its superelasticity and martensitic detwinning processes (as seen from AFM images shown in Figs. 3, 4). Such resistance to cracks (even under sharp Berkovich indenter) can be important in developing coating materials for localised stress-sensitive applications.

Figure 7 and Table 2 summarise schematic presentations of distinct $P-h$ profiles during an instrumented indentation test using the equal displacement approach. Linking of the $P-h$ profiles with the pseudo-elastic effect will strongly depend on the nature of the indentation's unloading profile. As mentioned earlier, this is based on the location of the final unloading co-ordinate $\left(h_{\mathrm{f}}, P_{\mathrm{f}}\right)$ : (a) Type I with $\left(h_{\mathrm{f}}=0, P_{\mathrm{f}}>0\right)$, (b) Type II with $\left(h_{\mathrm{f}}=0, P_{\mathrm{f}}=0\right)$, (c) Type IIIA with $\left(h_{\mathrm{f}}>0, P_{\mathrm{f}}>0\right)$ and Type IIIB with $\left(h_{\mathrm{f}}=0, P_{\mathrm{f}}>0\right)$, and (d) Type IV with $\left(h_{\mathrm{f}}<0, P_{\mathrm{f}}=\right.$ $\left.P_{\max }\right)$. The Type IIIA is a profile where the last unloading force is above the first loading curve, and Type IIIB is a profile where the last unloading force is below the first loading curve (where $P_{\mathrm{L}}$ and $P_{\mathrm{U}}$ are loading and unloading forces, respectively, at an equal displacement), $h_{\mathrm{m}}$ is the maximum displacement, $h_{\mathrm{e}}$ is the equal displacement, $h_{\mathrm{f}}$ is the final displacement and $P_{\mathrm{f}}$ is corresponding force). 


\section{(i) BERKOVICH INDENTER}

(a) Depth vs. time plot

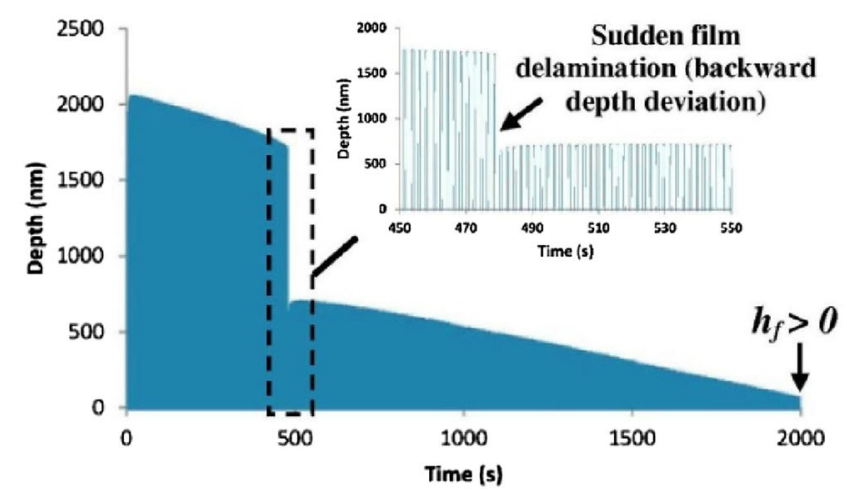

(b) AFM image

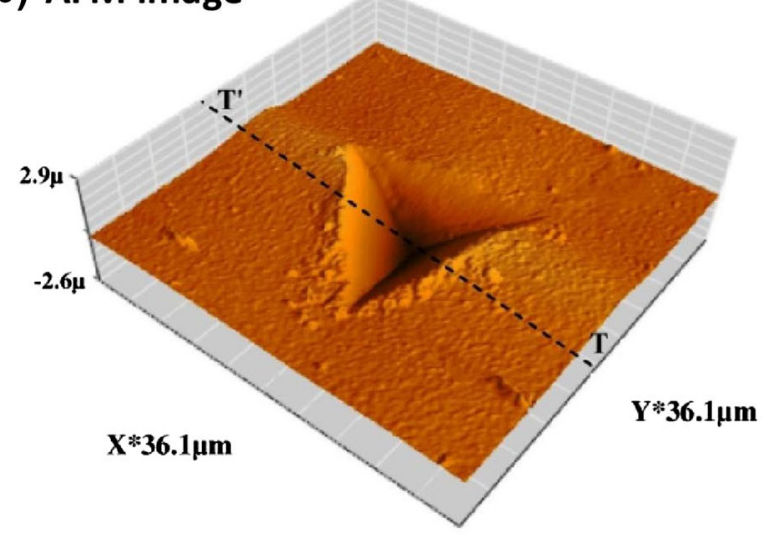

(c) Topography

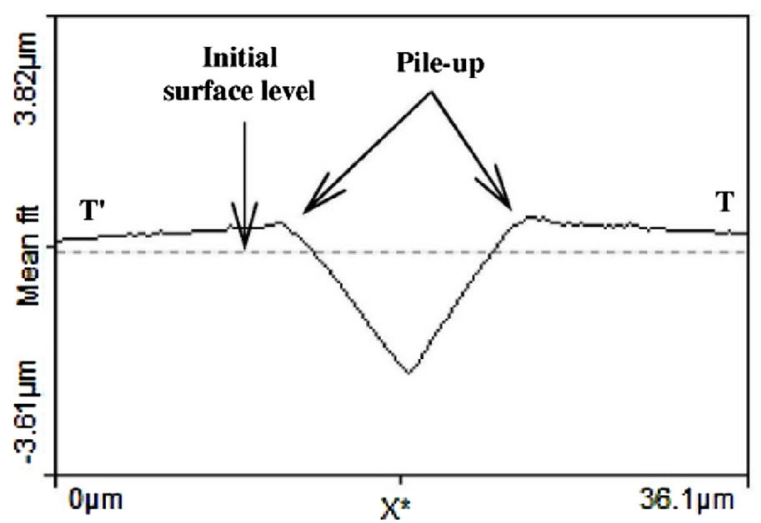

(ii) CONICAL INDENTER
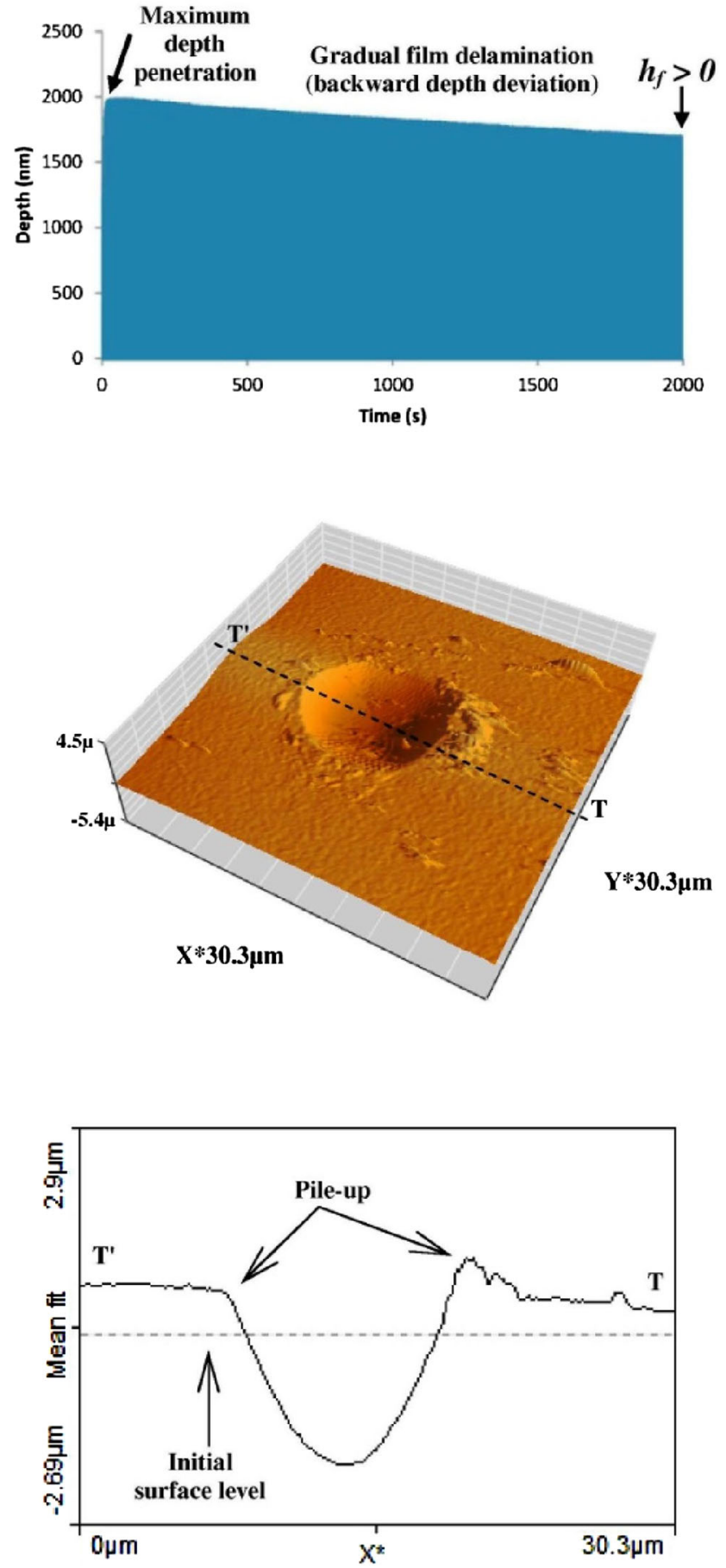

Fig. 5 Nano-impact testing of functionally graded TiN/TiNi at $100 \mathrm{mN}$ load: a full record of impact depth-time measurement, b corresponding AFM image, and $\mathbf{c}$ topography passing through the centre of residual impression indicated with a dotted line in (b) 
Table 1 Summary of nanoimpact (fatigue) depth-time profile characteristics

\begin{tabular}{llllll}
\hline Imapct load, $\mathrm{P}(\mathrm{mN})$ & \multicolumn{2}{l}{ Berkovich indenter } & & \multicolumn{2}{l}{ Conical indenter } \\
\cline { 2 - 3 } & FD out of 5 & BD out of 5 & & FD out of 5 & BD out of 5 \\
\hline 0.5 & 0 & $5 ; *(3+, 2-)$ & & 0 & $5 ; *(0+, 5-)$ \\
1 & 5 & 0 & & 0 & $5 ; *(0+, 5-)$ \\
10 & 0 & $5 ; *(4+, 1-)$ & & 0 & $5 ; *(3+, 2-)$ \\
100 & 0 & $5 ; *(3+, 2-)$ & & 1 & $4 ; *(4+, 0-)$ \\
\hline
\end{tabular}

$F D$ forward depth deviation, $B D$ backward depth deviation (data in the asterisk marked brackets indicate the occurrence and the type of backward depth deviation where minus sign $(-)$ indicate that the final impact depth is below zero, $h<0$; plus sign $(+)$ indicate that the final impact depth is above zero, $h>0$ )
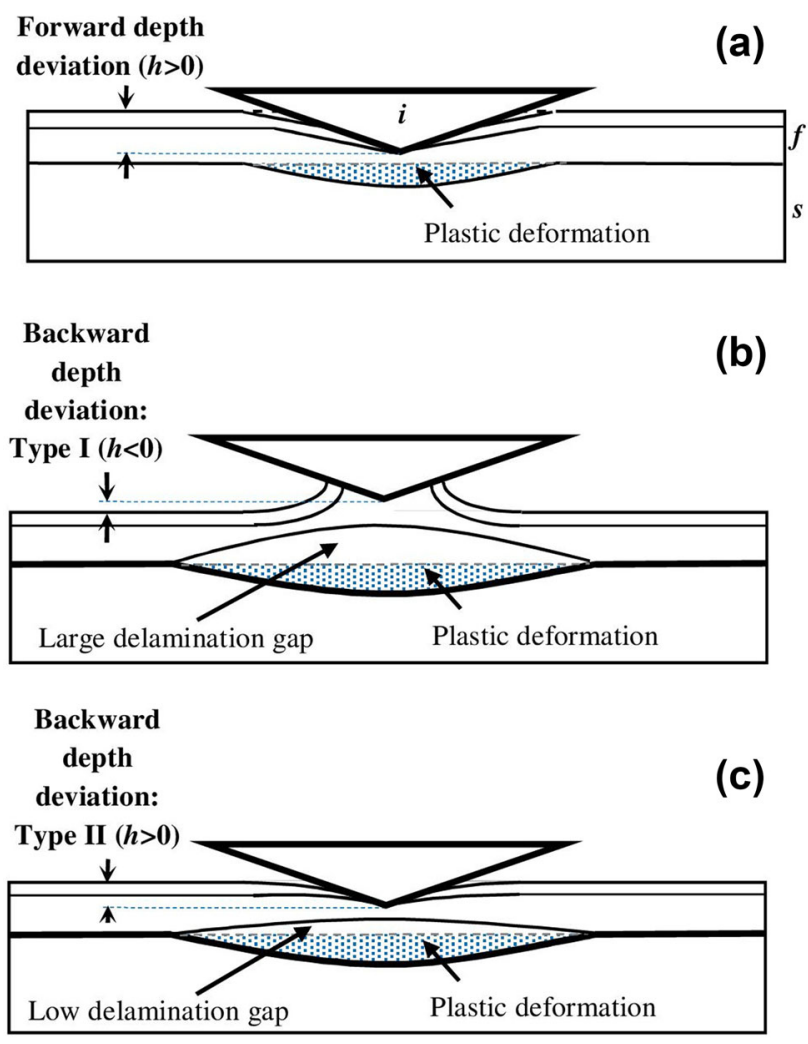

Fig. 6 Schematic of thin-film behaviour during nano-impact (fatigue) under Berkovich (or conical) indenter showing the types of depth deviation: a Forward depth deviation. b Backward depth deviation of type I. c Backward depth deviation of type II. $f$ film, $s$ substrate, $i$ indenter

\section{Comparison of Simulation and Experimental Results for Nanoindentation Contact}

The simulation results of indentation contact have been obtained to understand the stress distribution at the graded layer/substrate system during indentation contact. Owing to the elastic behaviour assumption in the simulation models (Fig. 8a), the stress concentration is quite high at certain locations in the models. These locations can be treated as the failure initiation zones (Fig. 8b, c). One such zone is the TiN-TiNi interface along which the stress is highly concentrated underneath the Berkovich indenter diagonal as seen in Fig. 8c(i). Also, there exists a large stress gradient across this interface, and the stress is highly tensile towards the top of the interface and a lower magnitude tensile under the interface. This might lead to delamination upon unloading because of the stress relief and consequent strain mismatch (Fig. 8b(i)). In the case of thin-film coatings, this translates to interfacial cracks initiating at the indenter centre and then propagating along the diagonal. The stress concentration has been observed more frequently at the interface between the TiNi-TiN coatings and not at the interface between the silicon substrate and the TiNi coating.

In conical indentation simulations, a large tensile stress was observed at the interface between the TiNi-TiN coatings and not much between the Si substrate and the TiNi coating interface (Fig. 8c(ii)). Hence, subsurface cracks can be expected to form at high loads. Similarly, a comparable magnitude of tensile stress was seen to be acting at the TiNi-TiN interface too. The Si-TiNi interface was at a larger differential stress state when compared to the Berkovich indentation. From Fig. 8b, there exists a large strain between the TiNi coating and the TiN across the interface. Compared to Berkovich indentation in which the strain mismatch is localised to a zone underneath the indentation, the strain mismatch appears over a larger volume in conical indentation. Similarly, the Si-TiNi interface is at a higher stress state when compared to the Berkovich indentation.

The subsurface stress and strain fields as seen is Fig. 8 can lead to interfacial strain and delamination without surface cracking. The above model does not include plasticity or any defects within materials and assumes the film is residual stress (pre-existing) free and perfectly bonded to the substrate; however, it provides an estimate of the elastic stress distribution to mimic the experimental results ("Single-Loading Cycle Nanoindentation, Multiple-Loading Cycle Nanoindentation", and "Nano-impact (Fatigue)—Berkovich and Conical Indenters" sections). Based on this model, it is expected that at loads lower than 500 $\mathrm{mN}$, the indentation or impact behaviour will also be dictated by the film adhesion properties and the underlying 
Fig. 7 Schematic presentation of distinct force-displacement profiles during an instrumented indentation test using the equal displacement approach based on final unloading co-ordinate $\left(h_{\mathrm{f}}\right.$, $\left.P_{\mathrm{f}}\right)$ : a Type I with $\left(h_{\mathrm{f}}=0\right.$, $\left.P_{\mathrm{f}}>0\right)$, b Type II with $\left(h_{\mathrm{f}}=0\right.$, $\left.P_{\mathrm{f}}=0\right)$, c Type IIIA with $\left(h_{\mathrm{f}}>0, P_{\mathrm{f}}>0\right)$ and Type IIIB with $\left(h_{\mathrm{f}}=0, P_{\mathrm{f}}>0\right)$, and d Type IV with $\left(h_{\mathrm{f}}<0\right.$, $P_{\mathrm{f}}=P_{\max }$ ). Type IIIA, where the last unloading force is above the first loading curve, and Type IIIB, where the last unloading force is below the first loading curve; $P_{\mathrm{L}}$ and $P_{\mathrm{U}}$ are the loading and unloading forces, respectively, at an equal displacement; $h_{\mathrm{m}}$ is the maximum displacement, $h_{\mathrm{e}}$ is the equal displacement, $h_{\mathrm{f}}$ is the final displacement and $P_{\mathrm{f}}$ is corresponding force. $O A$ loading, $A B$ holding, $B C$ unloading] (a)

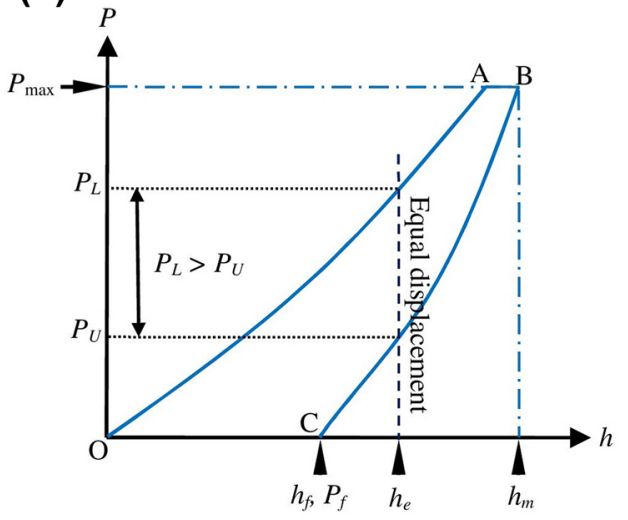

(b)

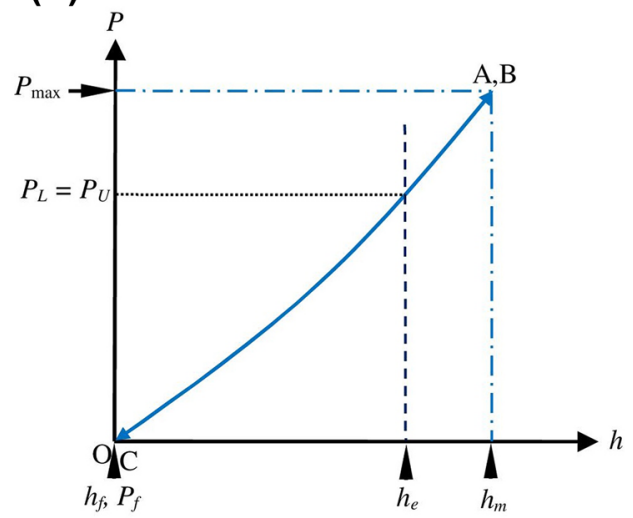

(c)

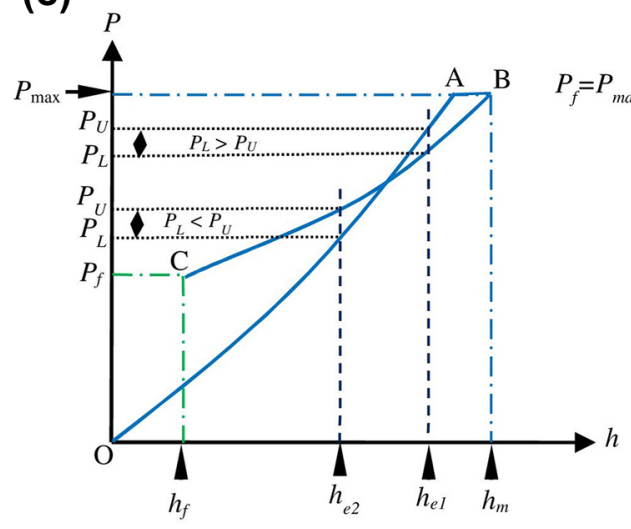

(d)

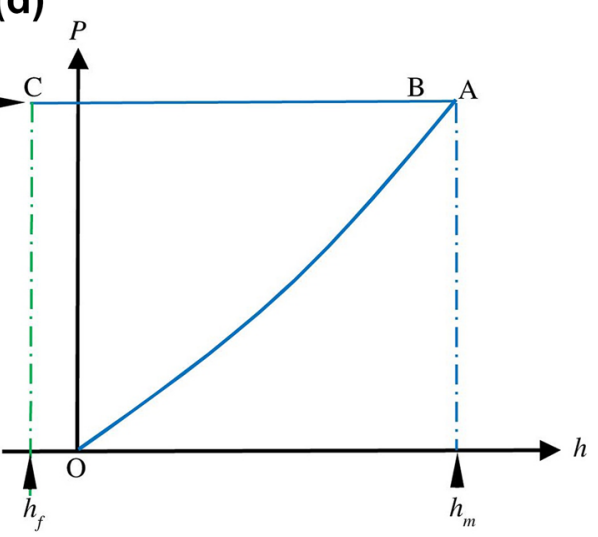

substrate. Regardless of some theoretical limitations (e.g. considering elastically deformable material, ignoring surface roughness, and taking coating and substrate as solid and homogeneous materials, excluding pseudo-elastic features in the model), the FE simulations of Berkovich and conical indentation on bilayer coating-substrate systems are in good agreement with the experimental findings to the observed surface features under AFM.

\section{Mechanical Response of Functionally Graded Thin Films}

Published research on the multiple-cycle nanoindentation and nano-impact (fatigue) response of TiNi films with a thin TiN top layer is limited, and this investigation provides insight into their failure mechanisms. Some recent examples for the similar work include nano-impact testing on $\mathrm{NiTi} / \mathrm{Pb}\left(\mathrm{Zr}_{0.52} \mathrm{Ti}_{0.48}\right) \mathrm{O}_{3}$ thin film (Choudhary et al. [54]. Temperature- and superelasticity-dependent phase transformations in bulk TiNi materials have, however, been a topic of research for several investigations (e.g. [55-57]. These investigations in bulk TiNi materials have concluded the importance of their fatigue resistances for industrial applications, which need to be considered in conjunction with the strain rate and temperature [56]. The experimental studies considered here in terms of multiple-cycle nanoindentation and nano-impact (fatigue) did not include the influence of temperature (or thermally)-induced phase transformations, as these tests were conducted at room temperature if the frictional heating at the indenter/film interface was below the austenitic transformation temperature. However, pseudo-elasticity still contributes to the deformation behaviour. By modelling the indentation as an elastic model (not elastic-plastic and superelastic), the FE simulations (Fig. 8) based on continuum mechanics indicated highly stressed (and hence highly strained) contact zone. Further studies that include temperature-induced shape memory and martensitic/austenitic phase transformations at nanoscale fatigue and multiple-cycle nanoindentation are therefore necessary to further develop the concepts of failure mechanisms concluded in this investigation.

This work concentrates on the phenomena which occur during nanoindentation and nano-impact and how the examination can be used to study more fundamental behaviour of materials such as deformation and fracture [58] (e.g. Fig. 9, only one example observed). The SEM image (Fig. 9) of nano-impact residual impression of functionally graded TiN/TiNi on Si substrate at $100 \mathrm{mN}$ load shows some distinct features of top layer tearing 
Table 2 Summary of multiple-loading cycle nanoindentation $P-h$ profile characteristics

\begin{tabular}{|c|c|c|c|c|c|}
\hline $\begin{array}{l}\text { Indenter } \\
\text { type }\end{array}$ & $\begin{array}{l}\text { Indentation (load } \\
\text { range, } \mathrm{mN} \text { ) }\end{array}$ & $\begin{array}{l}\text { No. of repeating } \\
\text { cycles }\end{array}$ & $\begin{array}{l}\text { No. of } \\
\text { repeats }\end{array}$ & $P-h$ profile characteristic & $P-h$ types \\
\hline \multirow[t]{4}{*}{ Berkovich } & $0.1-1$ & 10 & 5 & $\begin{array}{l}\text { Hysteresis-based forward and backward depth } \\
\text { deviation } \\
4 \text { final residual co-ordinate }\left(h_{\mathrm{f}}>0, P_{\mathrm{f}}>0\right) \\
1 \text { final residual co-ordinate }\left(h_{\mathrm{f}}=0, P_{\mathrm{f}}>0\right)\end{array}$ & $\begin{array}{l}\text { Type III(A): }\left(h_{\mathrm{f}}>0,\right. \\
\left.\quad P_{\mathrm{f}}>0\right) \\
\text { Type III }(\mathrm{B}):\left(h_{\mathrm{f}}=0,\right. \\
\left.\quad P_{\mathrm{f}}>0\right)\end{array}$ \\
\hline & $1-10$ & 10 & 5 & $\begin{array}{l}\text { Hysteresis-based forward and backward depth } \\
\text { deviation } \\
5 \text { final residual co-ordinate }\left(h_{\mathrm{f}}=0, P_{\mathrm{f}}>0\right)\end{array}$ & $\begin{array}{l}\text { Type III }(\mathrm{B}):\left(h_{\mathrm{f}}=0,\right. \\
\left.P_{\mathrm{f}}>0\right)\end{array}$ \\
\hline & $10-100$ & 10 & 5 & $\begin{array}{l}\text { Forward depth deviation } \\
\text { Viscoelastic rebound during each loading cycles } \\
\text { for each test runs } \\
5 \text { final residual co-ordinate }\left(h_{\mathrm{f}}=0, P_{\mathrm{f}}>0\right)\end{array}$ & $\begin{array}{l}\text { Type I: }\left(h_{\mathrm{f}}=0,\right. \\
\left.P_{\mathrm{f}}>0\right)\end{array}$ \\
\hline & $100-500$ & 10 & 5 & $\begin{array}{l}\text { Forward depth deviation } \\
\text { Viscoelastic rebound during each loading cycles } \\
\text { for each test runs } \\
5 \text { final residual co-ordinate }\left(h_{\mathrm{f}}=0, P_{\mathrm{f}}>0\right)\end{array}$ & $\begin{array}{l}\text { Type I: }\left(h_{\mathrm{f}}=0,\right. \\
\left.P_{\mathrm{f}}>0\right)\end{array}$ \\
\hline \multirow[t]{4}{*}{ Conical } & $0.1-1$ & 10 & 5 & $\begin{array}{l}\text { Backward depth deviation } \\
4 \text { final residual co-ordinate }\left(h_{\mathrm{f}}<0, P_{\mathrm{f}}=P_{\max }\right) \\
1 \text { final residual co-ordinate }\left(h_{\mathrm{f}}>0, P_{\mathrm{f}}>0\right)\end{array}$ & $\begin{array}{l}\text { Type III }(\mathrm{A}):\left(h_{\mathrm{f}}>0,\right. \\
\left.P_{\mathrm{f}}>0\right) \\
\text { Type IV: }\left(h_{\mathrm{f}}<0,\right. \\
\left.P_{\mathrm{f}}=P_{\max }\right)\end{array}$ \\
\hline & $1-10$ & 10 & 5 & $\begin{array}{l}\text { Hysteresis-based forward and backward depth } \\
\text { deviation } \\
4 \text { final residual co-ordinate }\left(h_{\mathrm{f}}=0, P_{\mathrm{f}}>0\right) \\
1 \text { final residual co-ordinate }\left(h_{\mathrm{f}}=0, P_{\mathrm{f}}=0\right)\end{array}$ & $\begin{array}{l}\text { Type III }(\mathrm{B}):\left(h_{\mathrm{f}}=0,\right. \\
\left.P_{\mathrm{f}}>0\right) \\
\text { Type II: }\left(h_{\mathrm{f}}=0,\right. \\
\left.P_{\mathrm{f}}=0\right)\end{array}$ \\
\hline & $10-100$ & 10 & 5 & $\begin{array}{l}\text { Forward depth deviation } \\
\text { Viscoelastic rebound during each loading cycles } \\
\text { for each test runs } \\
5 \text { final residual co-ordinate }\left(h_{\mathrm{f}}=0, P_{\mathrm{f}}>0\right)\end{array}$ & $\begin{array}{l}\text { Type I: }\left(h_{\mathrm{f}}=0,\right. \\
\left.\quad P_{\mathrm{f}}>0\right)\end{array}$ \\
\hline & $100-500$ & 10 & 5 & $\begin{array}{l}\text { Forward depth deviation } \\
\text { Viscoelastic rebound during each loading cycles } \\
\text { for each test runs } \\
5 \text { final residual co-ordinate }\left(h_{\mathrm{f}}=0, P_{\mathrm{f}}>0\right)\end{array}$ & $\begin{array}{l}\text { Type I: }\left(h_{\mathrm{f}}=0,\right. \\
\left.\quad P_{\mathrm{f}}>0\right)\end{array}$ \\
\hline
\end{tabular}

leading to significant residual stress relaxation, revealing some other features existing at the nano-impact edge due to high concentration of impact tensile stresses.

There are two aspects of applications of nanomechanical techniques which make it unique: (i) enhancing the understanding of the evolution of material behaviour, and (ii) qualitative and quantitative evaluation of mechanical properties such as deformation and fracture. Both aspects have the potential to improve our understanding of the structure-property relationships of current and future generation shape memory alloy materials. In addition, the knowledge developed here can be incorporated to improve the nanomechanical-based condition monitoring systems for stress-critical applications. However, with some limitations, it is summarised here that nanomechanical testing has considerable scopes to assess complex deformation and fracture properties of nitinol-based materials. With the advancement of thin-film nitinol and their composites, it is anticipated that the materials' responses measured during nanomechanical testing will be critical for enhancing our understanding of future-generation shape memory alloy applications [59].

\section{Conclusions}

Microstructures of the graded TiN/TiNi thin films have been studied using DSC, XRD and XPS. Their nanoindentation and fatigue properties were studied using multiple-load cycle nanoindentation and nano-impact tests. The following conclusions were drawn:

(i) DSC profile confirmed the occurrence of the martensitic transformations during heating and cooling and that a thin layer of TiN did not change 


\section{(i) Berkovich indentation}

(a) Illustration of 3D elastic finite element modelling

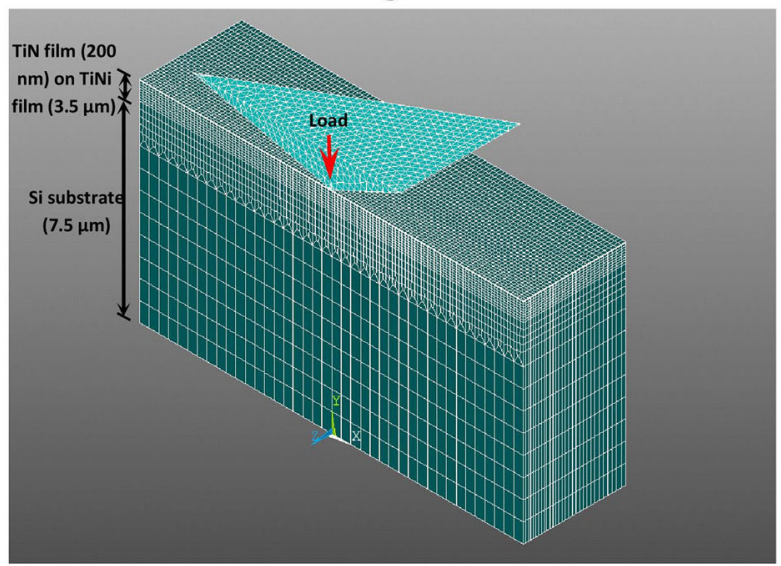

(b) Elastic strain distribution (zoomed view at indent zone)

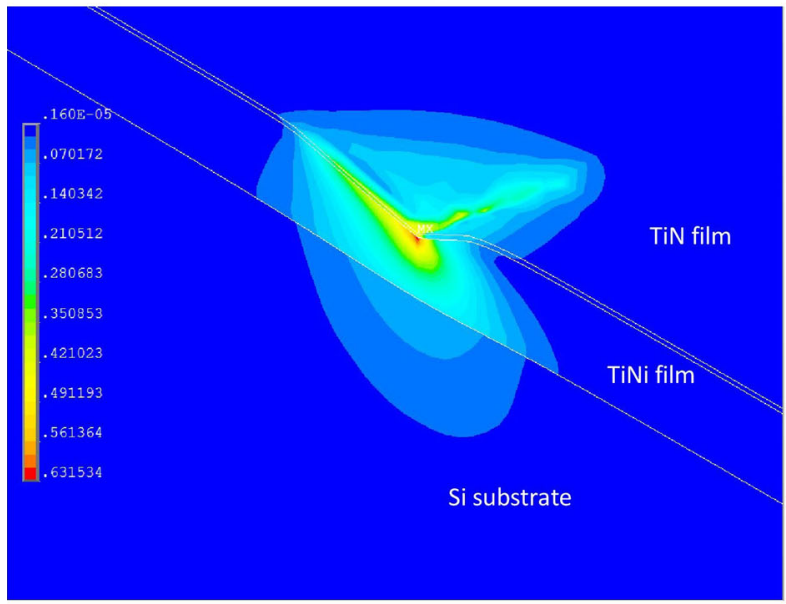

(c) von-Mises stress distribution (zoomed view at indent zone)

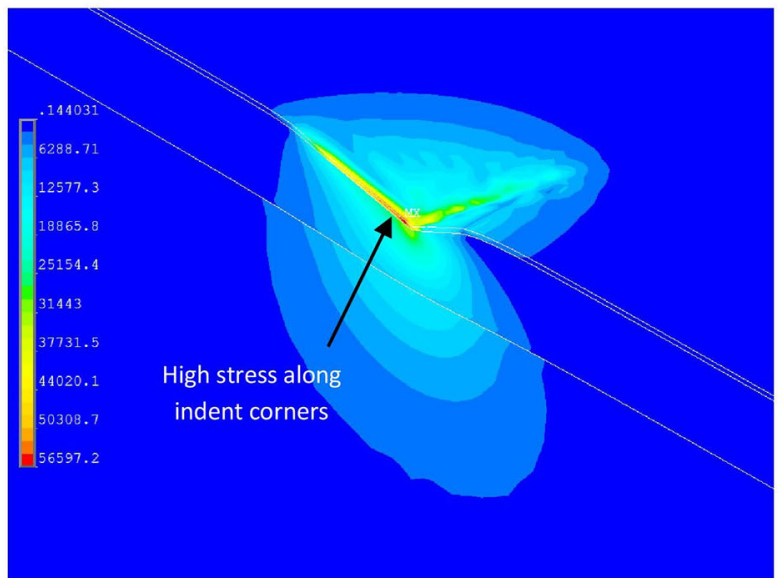

(ii) Conical indentation
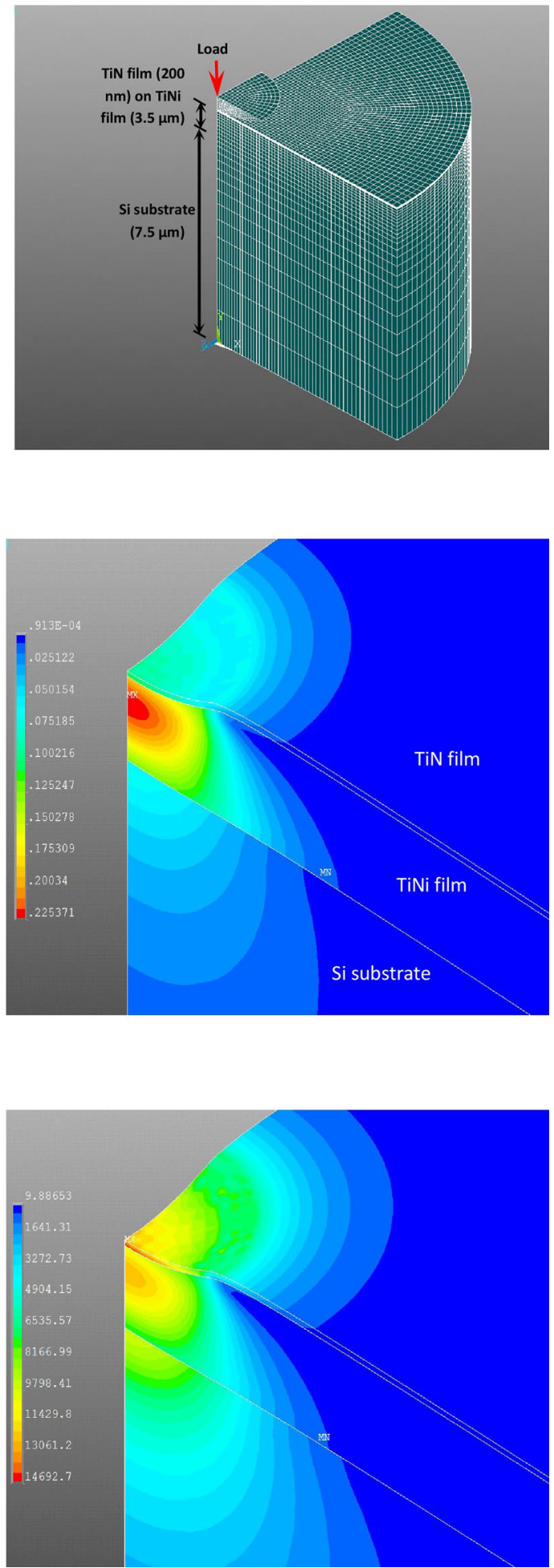

Fig. 8 3D elastic finite-element modelling at $500 \mathrm{mN}$ load shown for TiN $(200 \mathrm{~nm})$ on TiNi $(3.5 \mu \mathrm{m})$ on $7.5-\mu \mathrm{m}$-thick $\mathrm{Si}$ substrate: (i) Berkovich, and (ii) conical diamond indenters (Stresses are in MPa) 

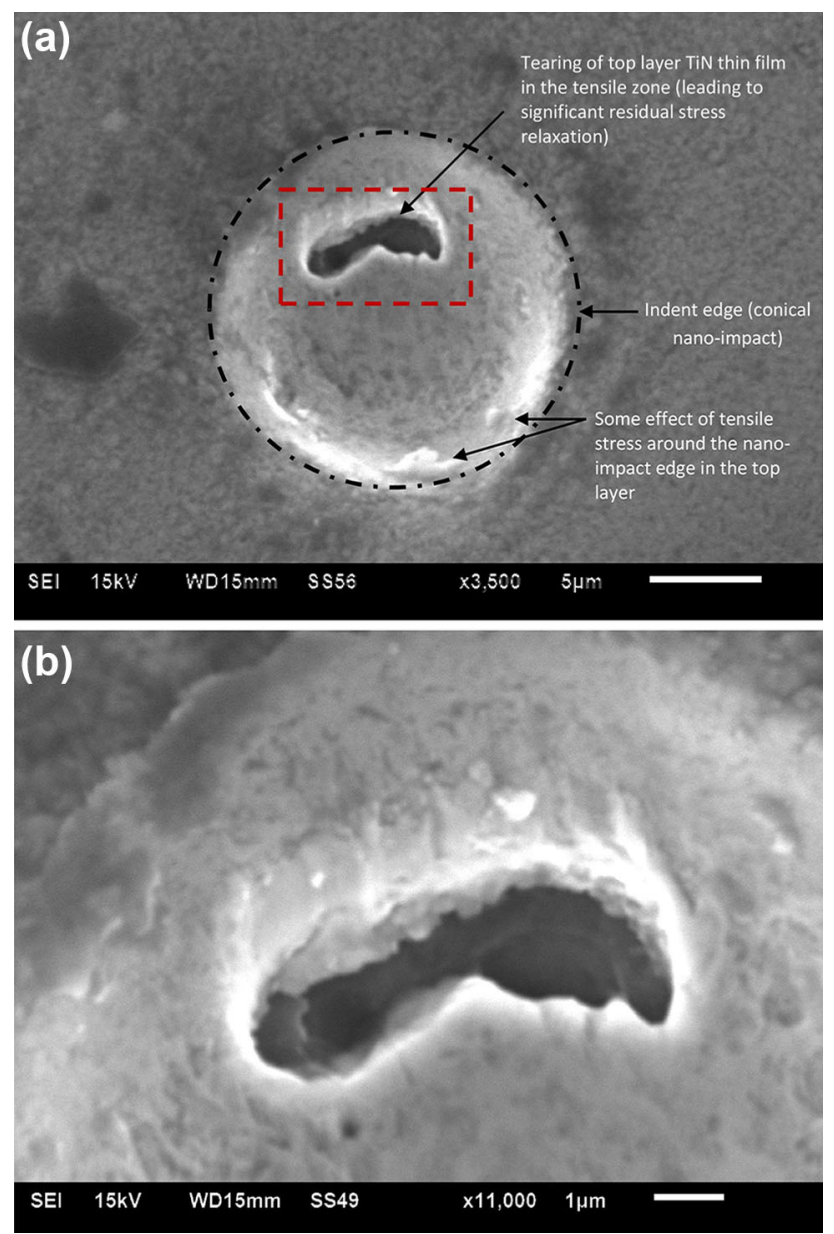

Fig. 9 SEM image of nano-impact residual impression of functionally graded TiN/TiNi at $100 \mathrm{mN}$ load: a showing some distinct features top layer tearing leading to significant residual stress relaxation, including some other features at the nano-impact edge due to high concentration of impact tensile stresses, and $\mathbf{b}$ magnified view of the region (boxed)

the phase-transformation behaviour. With the TiN protective layer on TiNi films, oxidation of the Ti has been prevented. XRD profiles confirm that the thin crystalline TiN layer physically resides on top of the TiNi film without noticeable phase disturbance to the underneath TiNi layer. XPS depth profile of the coating system indicates that a 100 -nm-thick top layer is of pure TiN, beneath which, a 200-nm transition layer exists on the original TiNi film. In the transition layer, composition grading occurs as $\mathrm{Ti}$ reduces to that in $\mathrm{TiNi}$, and $\mathrm{N}$ gradually vanishes off. In the TiN top layer, certain amounts of $\mathrm{N}$ atoms are found to exist in the interstitial site of the TiN structure.

(ii) The geometrical shapes of the indenter test probe (Berkovich or conical) and the indentation load range were critical in inducing localised indentation cyclic stress, leading to distinct film failure mechanism and pseudo-elastic effect at a lower load range. Based on the depth deviation, and supplemented by AFM observations of indentations, four types of the $P-h$ profiles were observed. In all cases, no surface cracking in the films was observed under any indenter tips. However, there may be some subsurface delaminations between TiN and NiTi layers and between $\mathrm{NiTi}$ and Si substrate, including cracking in the $\mathrm{Si}$ substrate at higher loads.

(iii) Indenter shape and nano-impact load had little influence on the type (forward or backward) of depth deviations. Due to nano-impact, the failure of films starts from delamination at the filmsubstrate interface, resulting in decrease in contact depth (backward depth deviation), and the delamination failure indicates the release of elastic stored energy (residual stress).

(iv) The elastic finite-element stress results are in good agreement with the experimental nanoindentation failure features of the top layer TiN film. The highest tensile stress occurs at the indentation corners, which can induce the edge cracking first in the coating surface. The location of maximum stress (von-Mises) near the film/substrate interface can indicate backward depth deviation using conical indenter. Other film properties such as localised adhesive strength, through-thickness residual stress profile, microstructure, and constitutive model for the comprehensive representation of the evolutionary response of SMAs also need to be considered in future studies for achieving improved indentation modelling.

Acknowledgement The authors acknowledge support from the UoA and CAPEX funding from Northumbria University at Newcastle upon Tyne, Royal Academy of Engineering-Research Exchange with China and India.

Open Access This article is distributed under the terms of the Creative Commons Attribution 4.0 International License (http://creative commons.org/licenses/by/4.0/), which permits unrestricted use, distribution, and reproduction in any medium, provided you give appropriate credit to the original author(s) and the source, provide a link to the Creative Commons license, and indicate if changes were made.

\section{References}

1. Fu YQ, Du H (2002) Relaxation and recovery of stress during martensite transformation for sputtered shape memory TiNi film. Surf Coat Technol 153:100-105

2. Fu YQ, Du HJ (2003) Effects of film composition and annealing on residual stress evolution for shape memory TiNi film. Mater Sci Eng A 342:236-245 
3. Fu YQ, Du H, Zhang S (2003) Deposition of TiN layer on TiNi thin films to improve surface properties. Surf Coat Technol 167:129-136

4. Huang WM, Su JF, Hong MH, Yang B (2005) Pile-up and sink-in in micro-indentation of a NiTi shape-memory alloy. Scr Mater 53:1055-1057

5. Kahn H, Huff MA, Heuer AH (1998) The TiNi shape-memory alloy and its applications for MEMS. J Micromech Microeng 8:213

6. Krulevitch P, Lee AP, Ramsey PB, Trevino JC, Hamilton J, Northrup MA (1996) Thin film shape memory alloy microactuators. J Microelectromech Syst 5:270-282

7. Miyazaki S, Hashinnaga T, Ishida A (1996) Martensitic transformations in sputter-deposited $\mathrm{Ti}-\mathrm{Ni}-\mathrm{Cu}$ shape memory alloy thin films. Thin Solid Films 281-282:364-367

8. Miyazaki S, Ishida A (1999) Martensitic transformation and shape memory behavior in sputter-deposited TiNi-base thin films. Mater Sci Eng A 273-275:106-133

9. Wayman CM (1992) Shape memory and related phenomena. Prog Mater Sci 36:203-224

10. Wei ZG, Sandstorm R (1998) Review. Shape-memory materials and hybrid composite for smart systems. Part I. Shape-memory materials. J Mater Sci 33:3743-3762

11. Wolf RH, Heuer AH (1995) TiNi (shape memory) films on silicon for MEMS applications. J Microelectromech Syst 4:206-212

12. Fu YQ, Du H, Huang WM, Zhang S, Hu M (2004) TiNi-based thin films in MEMS applications: a review. Sens Actuators A 112:395-408

13. Fu YQ, Luo JK, Hu M, Du H, Flewitt AJ, Milne WI (2005) Micromirror structure actuated by TiNi shape memory thin films. J Micromech Microeng 15:1872-1877

14. Fu YQ, Luo JK, Flewitt AJ, Ong SE, Zhang S, Du H, Milne WI (2007) Micro-actuators of free-standing TiNiCu Films. Smart Mater Struct 16:2651-2657

15. Fu YQ, Luo JK, Ong SE, Zhang S, Flewitt AJ, Milne WI Shape memory microcage of TiNi/DLC films for biological applications. J Micromech Microeng. 18, art no. 035026 (2008)

16. Filip P, Lausmaa J, Musialek J, Mazanec K (2001) Structure and surface of TiNi human implants. Biomaterials 22:2131-2138

17. Shabalovskaya SA (1996) On the nature of the biocompatibility and on medical application of TiNi shape memory and superelastic alloys. Bio Med Mater Eng 6:267-289

18. Lin HC, Liao HM, He JL, Lin KM, Chen KC (1997) Wear characteristics of ion-nitrided $\mathrm{Ti}_{50} \mathrm{Ni}_{50}$ shape memory alloys. Surf Coat Technol 92:178-189

19. Starosvesky D, Gotman I (2001) TiN coating improves the corrosion behavior of superelastic NiTi surgical alloy. Surf Coat Technol 148:268-276

20. Green SM, Grant DM, Wood JV (1997) XPS characterisation of surface modified Ni-Ti shape memory alloy. Mater Sci Eng A 224:21-26

21. Hernandez R, Polizu S, Turenne S, Yahia LH (2002) Characteristics of porous nickel-titanium alloys for medical applications. Bio Med Mater Eng 12:37-45

22. Wu MJ, Huang WM, Fu YQ, Chollet F, Hu YY, Cai M (2009) Reversible surface morphology in shape-memory alloy thin films. J Appl Phys 105:033517

23. Tan L, Crone WC (2002) Surface characterization of NiTi modified by plasma source ion implantation. Acta Mater 50:4449-4460

24. Wu SK, Chu CL, Lin HC (1997) Ion nitriding of TiNi shape memory alloys I. Nitriding parameters and microstructure characterization. Surf Coat Technol 92:197-205

25. Zhao X, Cai W, Zhao L (2002) Corrosion behavior of phosphorus ion-implanted $\mathrm{Ni}_{50.6} \mathrm{Ti}_{49.4}$ shape memory alloy. Surf Coat Technol 155:236-238
26. Gil FJ, Solano E, Campos A, Boccio F, Saez I, Alfonso MV, Planell JA (1998) Improvement of the friction behaviour of NiTi orthodontic archwires by nitrogen diffusion. Bio Med Mater Eng $8: 335-342$

27. Wu SK, Lin HC, Lee CY (1999) Gas nitriding of an equiatomic TiNi shape memory alloy: iI. Hardness, wear and shape memory ability. Surf Coat Technol 113:13-16

28. Wu SK, Lin HC, Lee CY (1999) Gas nitriding of an equiatomic TiNi shape-memory alloy: part I. Nitriding parameters and microstructure characterization. Surf Coat Technol 113:17-24

29. Kimura H, Sohmura T (1987) Surface coating on TiNi shape memory implant alloys. Dent Mater Apparatus 6:73

30. Fu YQ, Du H (2003) Functionally graded TiN/TiNi shape memory alloy thin films. Mater Lett 57:2995-2999

31. Amini A, Chung C, Kan Q, Naebe M, Song H (2013) Phase transformation evolution in NiTi shape memory alloy under cyclic nanoindentation loadings at dissimilar rates. Sci Rep $3: 3412$

32. Faisal NH, Ahmed R, Fu YQ (2012) Nano-impact and fatigue characterization of as-deposited nitinol film. Coatings 2:195-209

33. Faisal NH, Ahmed R, Fu YQ, Elakwah YO, Alhoshan M (2012) Influence of nanoindenter shape on DLC film failure during multiple-load cycle nanoindentation. Mater Sci Technol 28:1186-1197

34. Pan G, Cao Z, Wei M, Xu L, Shi J, Meng X (2014) Superelasticity of TiNi thin films induced by cyclic nanoindentation deformation at nanoscale. Mater Sci Eng A 600:8-11

35. Pan G, Cao Z, Shi J, Wei M, Xu L, Meng X (2014) Different mechanical response of TiNi film induced by the shape of indenter during nanoindentation. Sens Actuators A 217:75-80

36. Wood AJM, Sanjabi S, Fu YQ, Barber ZH, Clyne TW (2008) Nanoindentation of binary and ternary Ni-Ti-based shape memory alloy thin films. Surf Coat Technol 202:3115-3120

37. Oliver WC, Pharr GM (1992) An improved technique for determining hardness and elastic modulus using load and displacement sensing indentation experiments. J Mater Res 7:1564-1583

38. Faisal NH, Ahmed R (2011) A review of patented methodologies in instrumented indentation residual stress measurements. Recent Pat Mech Eng 4:138-152

39. Fu YQ, Du H, Zhang S (2003) TiNi SMA thin films: relationship among processing, stress evolution and transformation properties. Surf Coat Technol 167:120-128

40. Bertoti I (2002) Characterization of nitride coatings by XPS. Surf Coat Technol 151-152:194-203

41. Delfino M, Fair JA, Hodul D (1992) X-ray photoemission spectra of reactively sputtered TiN. J Appl Phys 71:6079-6085

42. Kovac J, Scarel G, Sancrotti M, Beghi MG, Bottani CE, Ossi PM, Calliari L, Bonelli M, Miotello A (1999) Time-dependent evolution of thin TiN films prepared by ion beam assisted deposition. J Appl Phys 86:5566

43. Vasile MJ, Emerson AB, Baiocchi FA (1990) The characterization of titanium nitride by $\mathrm{x}$-ray photoelectron spectroscopy and Rutherford backscattering. J Vacuum Sci Technol A 8:99

44. Prieto P, Kirby RE (1995) X-ray photoelectron spectroscopy study of the difference between reactively evaporated and direct sputter-deposited TiN films and their oxidation properties. J Vacuum Sci Technol A 13:2819

45. Faisal NH, Ahmed R, Fu YQ, Abuhimd HM (2012b) Nano-impact characterization of TiN/Ti0.5Ni0.5 thin film shape memory alloy. In: The 2nd Saudi international nanotechnology conference (2SINC). 11-13 Nov, 2012, KACST, Riyadh

46. Faisal NH, Ahmed R, Fu YQ, Hadfield M, Alhoshan M (2012d) DLC film behaviour during multiple-cycle repeating nanoindentation. WIT Trans Eng Sci Tribol Des II 76: 43-54, ISSN 1743-3533

47. Faisal NH, Ahmed R, Goel S, Fu YQ (2014) Influence of test methodology and probe geometry on nanoscale fatigue 
mechanisms of diamond-like carbon thin film. Surf Coat Technol 242:42-53

48. Huang J-H, Ouyang F-Y, Yu G-P (2007) Effect of film thickness and $\mathrm{Ti}$ interlayer on the structure and properties of nanocrystalline TiN thin films on AISI D2 steel. Surf Coat Technol 201:7043-7053

49. Tong LB, Li YH, Meng FL, Tian HW, Zheng WT, Wang YM (2010) Investigation on mechanical properties of sputtered TiNi thin films. J Alloy Compd 494:166-168

50. Ahmed R, Fu YQ, Faisal NH (2012) Fatigue at nanoscale: an integrated stiffness and depth sensing approach to understand the mechanisms of failure in DLC film. ASME J Tribol 134: 8. art no. 012001

51. Zhang X, Zhang S, Beake BD (2015) Toughness evaluation of thin hard coatings and films. In: Zhang $S$ (eds) Thin films and coatings: toughening and toughness characterization, pp. 48-121, CRC Press. (ISBN 9781482222906)

52. Yan W, Sun Q, Feng XQ, Qian L (2007) Analysis of spherical indentation of superelastic shape memory allots. Int $\mathrm{J}$ Solids Struct 44:1-17

53. Faisal NH, Ahmed R, Reuben RL (2011) Indentation testing and its acoustic emission response: applications and emerging trends. Int Mater Rev 56:98-142
54. Choudhary N, Kharat DK, Humbeeck JV, Kaur D (2013) NiTi/ $\mathrm{Pb}(\mathrm{Zr} 0.52 \mathrm{Ti} 0.48) \mathrm{O} 3$ thin film heterostructures for vibration damping in MEMS. Sens Actuators A 193:30-34

55. Ma J, Karaman I, Noebe RD (2010) High temperature shape memory alloys. Int Mater Rev 55:257-315

56. Tobushi H, Shimeno Y, Hachisuka T, Tanaka K (1998) Influence of strain rate on superelastic properties of TiNi shape memory alloy. Mech Mater 30:141-150

57. Zhang Y, Cheng Y-T, Grummon DS (2005) Indentation stress dependence of the temperature range of microscopic superelastic behavior of nickel-titanium thin films. J Appl Phys 98:033505

58. Beake BD, Fox-Rabinovich GS, Veldhuis SC, Goodes SR (2009) Coating optimisation for high speed machining with advanced nanomechanical test methods. Surf Coat Technol 203:1919-1925

59. Callisti M, Danek M, Yasuda K, Evaristo M, Tichelaar FD, Cavaleiro A, Polcar T (2015) Ni-Ti(-Cu) shape memory alloy interlayers supporting low friction functional coatings. Tribol Int 88:135-142 